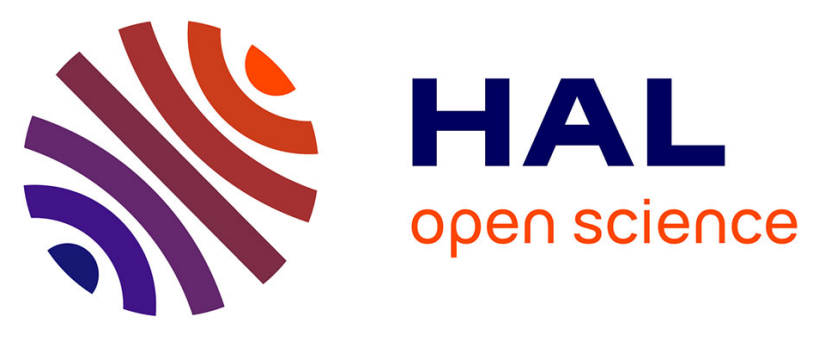

\title{
Repurposing rotavirus vaccines for intratumoral immunotherapy can overcome resistance to immune checkpoint blockade
}

Tala Shekarian, Eva Sivado, Anne-Catherine Jallas, Stephane Depil, Janice

Kielbassa, Isabelle Janoueix-Lerosey, Gregor Hutter, Nadège Goutagny, Christophe Bergeron, Alain Viari, et al.

\section{To cite this version:}

Tala Shekarian, Eva Sivado, Anne-Catherine Jallas, Stephane Depil, Janice Kielbassa, et al.. Repurposing rotavirus vaccines for intratumoral immunotherapy can overcome resistance to immune checkpoint blockade. Science Translational Medicine, 2019, 11 (515), pp.eaat5025. 10.1126/scitranslmed.aat5025 . hal-02347852

\section{HAL Id: hal-02347852 \\ https://hal.inria.fr/hal-02347852}

Submitted on 5 Nov 2019

HAL is a multi-disciplinary open access archive for the deposit and dissemination of scientific research documents, whether they are published or not. The documents may come from teaching and research institutions in France or abroad, or from public or private research centers.
L'archive ouverte pluridisciplinaire HAL, est destinée au dépôt et à la diffusion de documents scientifiques de niveau recherche, publiés ou non, émanant des établissements d'enseignement et de recherche français ou étrangers, des laboratoires publics ou privés. 


\title{
Repurposing rotavirus vaccines for intratumoral immunotherapy can overcome resistance to immune checkpoint blockade
}

\author{
Tala Shekarian $^{1,2,3,4}$, Eva Sivado ${ }^{2,3,5}$, Anne-Catherine Jallas ${ }^{2,5}$, Stéphane Depil ${ }^{1,2,3}$, \\ Janice Kielbassa ${ }^{6}$, Isabelle Janoueix-Lerosey ${ }^{7,8}$, Gregor Hutter ${ }^{4}$, Nadège Goutagny ${ }^{1,2}$, \\ Christophe Bergeron ${ }^{2,9}$, Alain Viari ${ }^{6,10}$, Sandrine Valsesia-Wittmann ${ }^{2,5 *}$, \\ Christophe Caux ${ }^{1,2 *}$, Aurélien Marabelle ${ }^{2,9,11,12 *}{ }^{\dagger}$
}

\begin{abstract}
Although immune checkpoint-targeted therapies are currently revolutionizing cancer care, only a minority of patients develop durable objective responses to anti-PD-1, PD-L1, and CTLA-4 therapy. Therefore, new therapeutic interventions are needed to increase the immunogenicity of tumors and overcome the resistance to these immunotherapies. Oncolytic properties of common viruses can be exploited for the priming of antitumor immunity, and such oncolytic viruses are currently in active clinical development in combination with immune checkpoint-targeted therapies. However, the routine implementation of these therapies is limited by their manufacturing constraints, the risk of exposure of clinical staff, and the ongoing regulations on genetically modified organisms. We sought to determine whether anti-infectious disease vaccines could be used as a commercially available source of immunostimulatory agents for cancer immunotherapy. We found that rotavirus vaccines have both immunostimulatory and oncolytic properties. In vitro, they can directly kill cancer cells with features of immunogenic cell death. In vivo, intratumoral rotavirus therapy has antitumor effects that are dependent on the immune system. In several immunocompetent murine tumor models, intratumoral rotavirus overcomes resistance to and synergizes with immune checkpointtargeted therapy. Heat- and UV-inactivated rotavirus lost their oncolytic activity but kept their synergy with immune checkpoint-targeted antibodies through the up-regulation of the double-stranded RNA receptor retinoic acid-induced gene 1 (RIG-I). Rotavirus vaccines are clinical-grade products used in pediatric and adult populations. Therefore, in situ immunization strategies with intratumoral-attenuated rotavirus could be implemented quickly in the clinic.
\end{abstract}

\section{INTRODUCTION}

Immune checkpoint blockade (ICB) therapies against programmed cell death protein-1 (PD-1), programmed death ligand-1 (PD-L1), and cytotoxic T-lymphocyte-associated protein 4 (CTLA-4) have demonstrated their clinical activity and have been approved in multiple cancers, including melanomas, squamous carcinomas of the lung, head and neck, and skin, urothelial carcinomas, renal cell carcinomas, Merkel cell carcinomas, mismatch repair-deficient tumors, hepatocarcinomas, gastric cancers, and Hodgkin's lymphoma $(1,2)$. However, only a minority of patients actually develop objective tumor responses with these new treatments. Several factors have been identified that correlate with effectiveness of ICB, notably PD-L1 expression in the tumor microenvironment (3), a high proportion

${ }^{1}$ Centre de Recherche en Cancérologie de Lyon (CRCL), UMR INSERM U1052 CNRS 5286 Université de Lyon, 69008 Lyon, France. ${ }^{2}$ Centre de Lutte contre le Cancer Léon Bérard, 69008 Lyon, France. ${ }^{3}$ Université Claude Bernard Lyon 1, 69100 Villeurbanne, France. ${ }^{4}$ University Hospital Basel, 4031 Basel, Switzerland. 5 INSERM UA8, 69008 Lyon, France. ${ }^{6}$ Synergie Lyon Cancer, Plateforme de bioinformatique 'Gilles Thomas', Centre Léon Bérard, 69008 Lyon, France. 'Institut Curie, PSL Research University, Inserm U830, 75005 Paris, France. ${ }^{8}$ SIREDO: Care, Innovation and Research for Children, Adolescents and Young Adults with Cancer, Institut Curie, 75005 Paris, France. ${ }^{9}$ Institut d'Hématologie et d'Oncologie Pédiatrique, Centre Léon Bérard, 69008 Lyon, France. ${ }^{10}$ Equipe Erable, INRIA Grenoble-Rhône-Alpes, 38330 Montbonnot-Saint Martin, France. ${ }^{11}$ Gustave Roussy, Université Paris-Saclay, Drug Development Department (DITEP), 94805 Villejuif, France. ${ }^{12}$ INSERM U1015, Gustave Roussy, 94805 Villejuif, France.

*These authors contributed equally to this work.

+Corresponding author. Email: aurelien.marabelle@gustaveroussy.fr of tumor-infiltrating T cells (4), and the existence of neoepitopes generated by high numbers of somatic point mutations in the cancer cells' genomes $(5,6)$. Other elements have been shown to contribute to the resistance to ICB such as immunosuppressive myeloid cells $(7,8)$, mutations in Janus kinase $1 / 2(9)$, and the absence of major histocompatibility complex I (MHC-I) expression by tumor cells (10). In this context, pediatric cancers, which display low $\mathrm{T}$ cell infiltrates, high myeloid cell infiltrates, and usually low mutational load, are poorly responsive to these immunotherapies (11-16). Intratumoral (IT) injections of oncolytic viruses, Toll-like receptor (TLR) agonists, or stimulator of interferon (IFN) gene agonists are in situ immunotherapy strategies currently in active clinical development with the aim of stimulating pattern recognition receptors (PRRs) for the priming of the antitumor immunity by turning noninfiltrated "cold" tumors into immune-infiltrated "hot" tumors $(17,18)$. IT stimulation of PRRs has shown promising results in patients with cancer by inducing effective antitumor immune responses, in both injected and noninjected sites (the so-called "abscopal effect") (19-22). In addition, IT PRR agonists and oncolytic viruses can overcome ICB resistance in syngeneic tumor models $(23-26)$ and patients with melanoma $(27,28)$.

Because the pediatric clinical development of PRR agonists will likely start many years after the development for adults, we sought to use anti-infectious disease vaccines as a potential source of clinical-grade PRR agonists to prime the antitumor immunity of pediatric cancers. Here, we report the preclinical rationale for an off-the-shelf and versatile strategy of IT immunotherapy, which could be easily translated to the clinic. 


\section{RESULTS}

\section{Rotavirus vaccines can activate nuclear factor- $\kappa B$ in a TLR- independent manner}

Because anti-infectious disease vaccines contain pathogens or pathogens extracts that stimulate PRR, we assessed whether they could be used as a clinical-grade source of PRR agonists. To evaluate the intrinsic ability of anti-infectious disease vaccines to stimulate TLRs, a major family of PRRs, we used transgenic HEK-293T (Human Embryonic Kidney) cell lines cotransfected individually with different TLRs and a luciferase reporter plasmid under the control of a nuclear factor $-\kappa \mathrm{B}(\mathrm{NF}-\kappa \mathrm{B})$ binding site. We incubated 10 different serial dilutions of 14 viral and bacterial anti-infectious disease vaccines with these transgenic cell lines and, 12 hours later, measured the luciferase bioluminescence intensity that proportionally correlated to NF- $\kappa \mathrm{B}$ induction. In these assays, we found that among the 14 evaluated vaccines, the typhoid fever vaccine (Tyavax) and the Mycobacterium tuberculosis vaccine (BCG Pasteur) were potent activators of TLR4 and TLR2, respectively (Fig. 1, A and B, and fig. S1). More unexpectedly, we found that, when used at midrange concentrations, the two rotavirus vaccines (Rotarix and Rotateq) were activating NF- $\kappa B$ in all the transgenic cell lines, including the parental 293T cell line devoid of TLR transgene (Fig. 1, C to E, and fig. S1). This observation suggested that these rotavirus vaccines were able to activate the NF- $\kappa B$ pathway independently of any TLR.

In addition, because no activation of NF- $\kappa \mathrm{B}$ was seen at high concentrations of the rotavirus vaccines, we suspected that such high concentrations could be toxic for the transgenic cell lines (Fig. 1, C and D). When looking at the viability of the parental cell line, we found a very low viability of cells at high concentration of rotavirus vaccines, as assessed by a sulforhodamine B (SRB) cell viability assay (Fig. 1F).

\section{Rotavirus vaccines have in vivo antitumor activity against a pediatric tumor model resistant to anti-CTLA-4 and anti-PD-L1 and have oncolytic properties}

The vaccines leading to NF- $\kappa \mathrm{B}$ activation were then evaluated for their therapeutic activity in a model of neuroblastoma (Neuro2a) that is resistant to anti-CTLA-4, anti-PD-1, anti-PD-L1, or their combinations (Fig. 2A). A/J mice were implanted with Neuro2a tumor cells in the flank and received IT treatment when tumors reached 0.7 to $1 \mathrm{~cm}$ in largest diameter, usually around day 7 after tumor inoculation. Although the Tyavax and BCG vaccines can activate TLR4 and TLR2, we could not find any notable therapeutic activity in this syngeneic pediatric tumor model upon IT injections of these vaccines compared to phosphate-buffered saline (PBS) injections $(P>0.05$; Fig. $2 \mathrm{~B})$. In contrast, when injected intratumorally, the rotavirus vaccines (Rotarix or Rotateq) had a significant $(P<0.005$ and $P<0.05$, respectively) antitumor activity observed in $50 \%$ of the Neuro2a neuroblastoma tumor-bearing mice (Fig. 2B).

On the basis of the earlier in vitro data, we hypothesized that the vaccines might have direct cytotoxic effects at high concentration, which could explain the in vivo antitumor activity. To confirm the intrinsic cytotoxic properties of rotavirus and eliminate the potential osmotic effects of the vaccine's excipients (additives), we tested the cytotoxic effects of the original rotavirus strains obtained from the manufacturer of the Rotateq vaccine [Merck Sharp \& Dohme Corp. (MSD)]. These five viral rotavirus strain preparations contained higher virus titers (100 to $1000 \times$ higher than in the Rotateq commercial vaccine) and were free of excipients.
First, we found that the Rotateq vaccine's excipient, which is mostly composed of concentrated carbohydrates, has partial osmotic cytotoxic effects against the SH-SY5Y human neuroblastoma cell line at high concentrations (1:20) but no effect at lower doses (Fig. 2C). Because the Rotateq vaccine is composed of five different rotavirus vaccine strains (G1, G2, G3, G4, and P1), we analyzed the cytotoxic properties of each individual strain on SH-SY5Y cells. We found that all five strains have potent cytotoxic properties [half maximal inhibitory concentration $\left(\mathrm{IC}_{50}\right)=$ from $1: 200,000$ to 1:2000] (Fig. 2D). Accordingly, increasing concentrations of the rotavirus viral strains showed a dose-dependent intrinsic cytotoxicity against SH-SY5Y cells $\left(\mathrm{IC}_{50}=1: 200,000\right)$, with higher potency compared to the more diluted vaccines, confirming a direct role of the virus on cell cytotoxicity (Fig. 2E).

To generalize the oncolytic properties of rotavirus, we repeated the SRB cytotoxic assay on a variety of human (Fig. 2F) and mouse (Fig. 2G) cancer cell lines. We found that despite the varying sensitivity of tumor cells, the rotavirus strains have dose-dependent cytotoxic effects on all cancer cell lines tested, although at lower potency for murine cell lines (Fig. 2G).

With the aim to evaluate the preferential cytotoxicity of rotavirus against cancer cells versus healthy cells (which defines oncolytic viruses), we further used primary (normal) human mammary epithelial cells (HMECs) and several primary cultures of fibroblasts in our SRB cytotoxic assay, using the same rotavirus strain dilutions and timing. We observed lower cytotoxic abilities of rotavirus on untransformed cells $\left(\mathrm{IC}_{50}=1: 200\right.$ for fibroblasts and 1:20 for HMEC) than on cancer cells ( IC $_{50}=1: 200,000$ to 1:2000 depending on the cancer cell line) (Fig. 2H).

We then inactivated the virus at $60^{\circ} \mathrm{C}$ for 4 hours followed by 2 hours of ultraviolet (UV) irradiation and repeated the SRB assay to evaluate the oncolytic ability of inactivated rotavirus on three different human cancer cell lines (A172, ACHN, and HEP3B). We observed that inactivated rotavirus preparations lost their cytotoxic effects on cancer cell lines (Fig. 2I). Together, these results confirmed the ability of rotavirus to preferentially kill cancer cells over normal cells, which is a common feature of oncolytic viruses.

\section{In vitro oncolytic properties of rotavirus strains translate into in vivo antitumor immunity}

We then studied the in vivo antitumor effects of different dilutions of IT rotavirus strains in different tumor models. After three consecutive IT injections every 3 days of pure versus diluted rotavirus in the A20 B cell lymphoma syngeneic model (Balb/c mice), we observed a potent antitumoral effect of rotavirus reaching $70 \%$ of treated mice with complete tumor regression including at the lowest dose (Fig. 3A, left and middle). This potent antitumor effect led to a cure for more than $50 \%$ of the mice (Fig. $3 \mathrm{~A}$, right). Working further at the 1:100 rotavirus dilution, we observed an antitumor activity in 30 to $40 \%$ of the mice in the neuroblastoma NXS2 (Fig. 3B, left and middle) and Neuro2a (Fig. 3C, left and middle) syngeneic tumor models (A/J mice) with significant benefits in overall survival observed only in the Neuro2a tumor model $(P=0.0001$; Fig. 3 , B and $\mathrm{C}$, right $)$.

To further demonstrate the role of the immune system in the in vivo antitumor activity of IT rotavirus therapy, we analyzed the tumor-infiltrating cells in the Neuro2a neuroblastoma tumor model by flow cytometry. Briefly, 24 hours after the first IT rotavirus injection, we quantified the $\mathrm{CD}_{11 \mathrm{~b}^{+}}$myeloid cell and $\mathrm{CD} 4^{+}$and $\mathrm{CD} 8^{+}$ 
Fig. 1. Proinflammatory features of vaccines. NF- $\kappa B$ activation in transgenic HEK-293 cell lines expressing specific Toll-like receptors (TLRs) and NF-KB-Luc reporter system by different dilutions of (A) M. tuberculosis vaccine (BCG Pasteur), (B) the typhoid fever vaccine (Tyavax), (C and D) rotavirus vaccines (Rotarix and Rotateq, respectively). Peptidoglycan (PG), lipopolysaccharide (LPS), and tumor necrosis factor- $\alpha$ (TNF- $\alpha$ ) were used as positive controls for stimulation of TLR2, TLR4 and NF- $\mathrm{\kappa B}$, respectively. Data are represented as RLU (relative luminescence unit) bioluminescence intensity. Red lines represent the activity of the natural ligand for the $T L R$, blue lines represent the activity of the vaccine, and the black line is the negative control (medium). Each data point is means \pm SEM; $n=3$ wells per dilution. The 293T parental cell line does not express any TLR but contains NF- $\kappa B$ reporter system. Other TLRs tested are shown in fig. S1. (E) Heatmap summarizing the NF- $\mathrm{kB}$ stimulatory properties across $14 \mathrm{vac}$ cines at optimal dilution (i.e. dilution providing the highest bioluminescence intensity) using the 293T transgenic reporter cell lines expressing specific TLRs and NF-KB-Luc reporter system. Normalization was performed with the corresponding natural TLR ligand at optimal dilution as a positive control (100\%). TLR9 and TLR6 cell lines have not been depicted because of the lack of positive control activation of the corresponding NF-KB cell lines by synthetic ligands. (F) Viability of 293T parental cell lines at different dilutions of Rotarix by SRB assay. Each data point is means \pm SEM; $n=3$ wells per dilution.
A

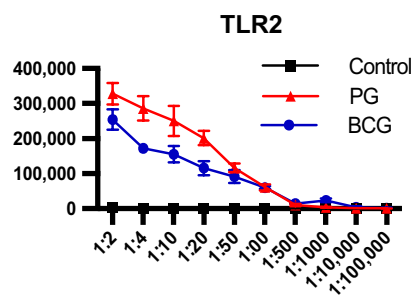

TLR2

Tyavax

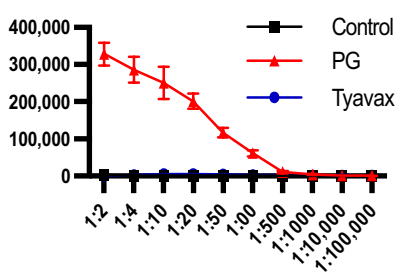

C

TLR2

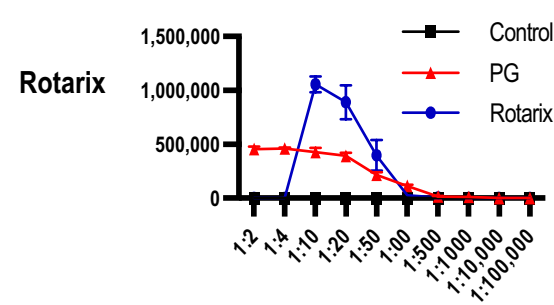

D

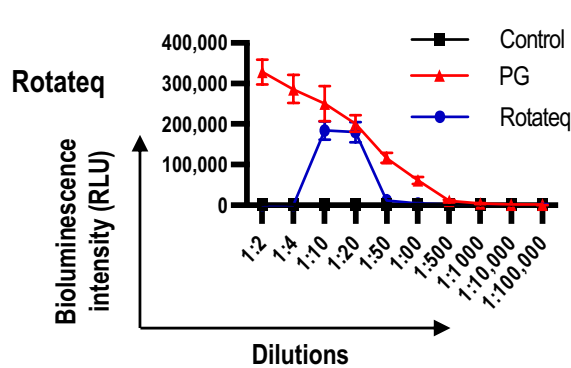

E

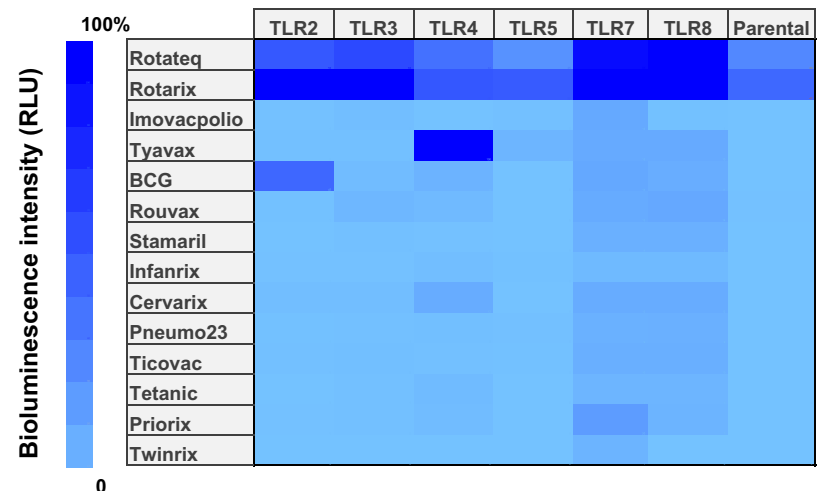

TLR4

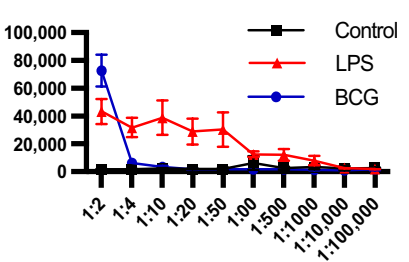

TLR4

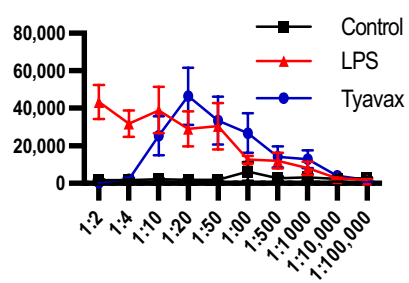

TLR4

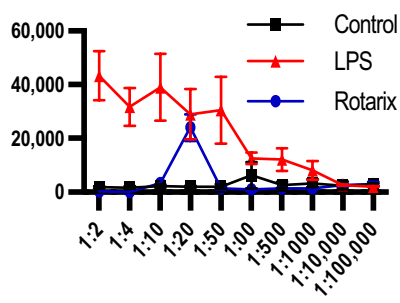

TLR4

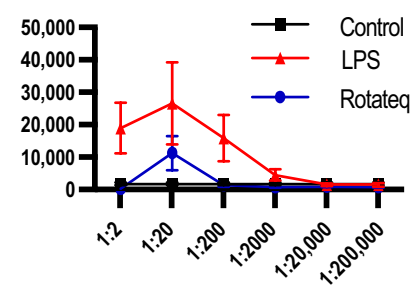

Parental cell line

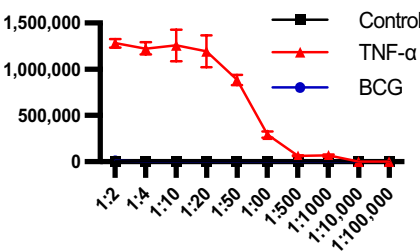

Parental cell line

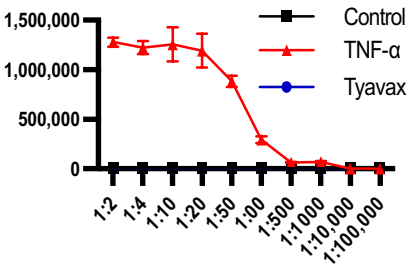

Parental cell line

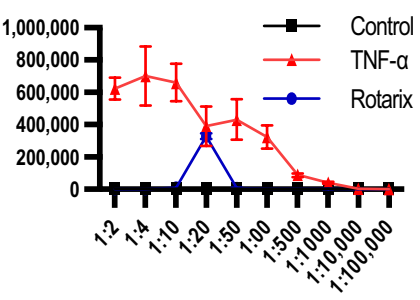

Parental cell line

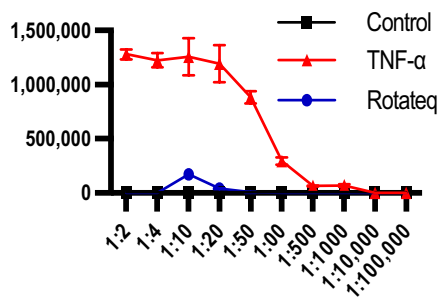

$\mathbf{F}$

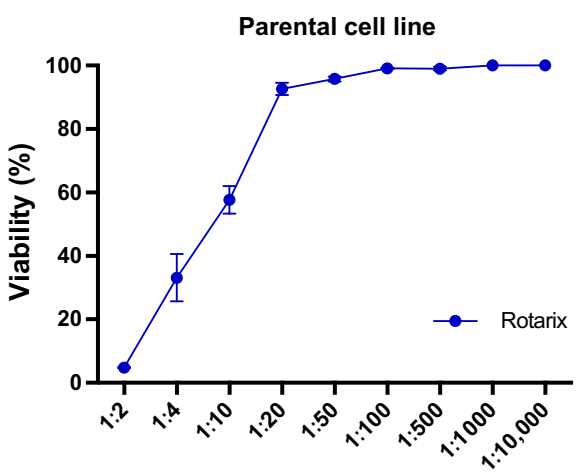

Dilutions

$\mathrm{T}$ cell proportions in the tumor infiltrates reported as a percentage of total $\mathrm{CD} 45^{+}$cells in tumors. We observed that the IT injection of rotavirus led to a rapid and remarkable increase in tumor-infiltrating myeloid cells from 30 to $70 \%$ of the tumor immune infiltrates, with no major variations in the $\mathrm{CD} 4, \mathrm{CD} 8$, and Foxp $3^{+} \mathrm{CD} 4^{+}$regulatory $\mathrm{T}$ cell $\left(\mathrm{T}_{\mathrm{reg}}\right)$ proportions (Fig. 3D, top). A significant proportion of 
Fig. 2. Rotavirus vaccines have in vivo antitumor activity against pediatric tumor models resistant to anti-CTLA-4 and anti-PD(L)1 and in vitro oncolytic properties against cancer cell lines. (A) Effects on the tumor growth of intraperitoneal (IP) injections of $200 \mu \mathrm{g}$ of anti-CTLA-4 $(\alpha C T L A-4)$ or anti-PD-(L)1 $(\alpha \mathrm{PD}-1 / \alpha \mathrm{PD}-\mathrm{L} 1)$ antibodies, either alone or in combination, in the murine Neuro2a neuroblastoma model (syngeneic to $A / J$ mouse strain background). Briefly, mice were injected subcutaneously with $5 \times 10^{6}$ of the Neuro2a murine tumor cell line. The therapy started at day 7 (black arrow) for a total of four injections with 3-day intervals. Tumors sizes were estimated as the product of their perpendicular diameters (in square millimeters). Every data point is the mean value of the tumor sizes from the mice belonging to the same treatment group at a given time point \pm SEM, $n=5$ to 10 mice per group. (B) Intratumoral (IT) injections of anti-infectious disease vaccines (BCG, Tyavax, Rotarix and Rotateq) in the Neuro2a syngeneic mouse tumor model. Three consecutive IT injections of $100 \mu \mathrm{l}$ of vaccines were performed every 3 days and starting around day 7 after tumor cells inoculation. $n=10$ mice per group each group was compared to IT PBS (unpaired one-tailed $t$ test); ns, not significant; ${ }^{*} P<0.05$ and ${ }^{*} P<0.005$. Cy totoxic effects were evaluated by SRB assay on the neuroblastoma human cell line (SH-SY5Y) after 5 days of incubation with (C) dilutions of the Rotateq excipient, (D) dilutions of the five pure rotavirus strains contained in the Rotateq vaccine (rotavirus

concentration, 10 to $100 \times$ higher than in the vaccine), (E) dilutions of the Rotateq vaccine (made of a mixture of $\sim 5.5 \times 10^{6} \mathrm{pfu} / \mathrm{ml}$ of five different rotavirus strains) versus pure rotavirus strains (mixture of five different rotavirus strains at $5.5 \times 10^{7}$ to $5.5 \times 10^{8} \mathrm{pfu} / \mathrm{ml}$ ). Means $\pm \mathrm{SEM}, n=3$ wells per dilution. Unpaired one-tailed $t$ test, ${ }^{*} P<0.05$, ${ }^{* * *} P<0.001$, and ${ }^{* * *} P<0.0001$. (F) $I C_{50}$ of rotavirus strains determined by cytotoxicity SRB assay on a variety of human cancer cell lines and (G) murine tumor cell lines. (H) IC ${ }_{50}$ of rotavirus strains determined by cytotoxicity SRB assay on normal cells (fibroblast and HMECs) compared to human triple-negative breast cancer (MDA-MB-231) and human neuroblastoma (SH-SY5Y) cancer cell lines. (I) $\mathrm{IC}_{50}$ of live versus inactivated rotavirus strains determined by cytotoxicity SRB assay on murine tumor cell lines. Serial dilution (1:10) was performed from 1:20 to 1:2,000,000. Incubation time of 3 to 5 days depending on the cell line. (F to I) Means \pm SEM, $n=3$ wells per dilution.

A Immune checkpoint antibodies against the neuroblastoma (Neuro2a) model
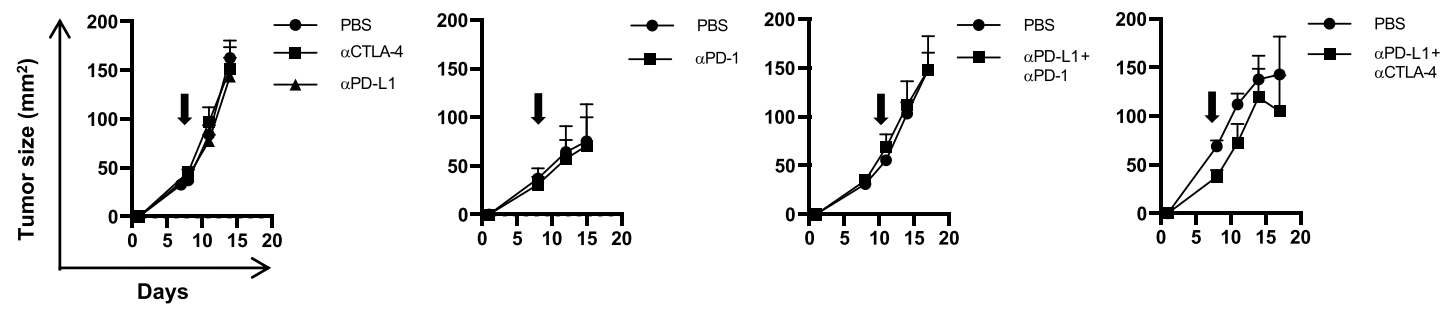

B PBS Tyavax
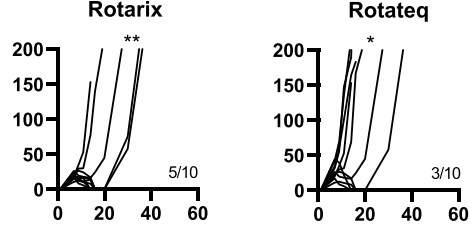

C Vaccine excipient on SH-SY5Y human

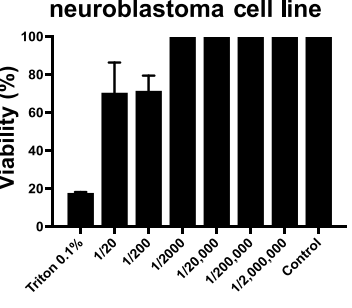

Dilutions

F

H

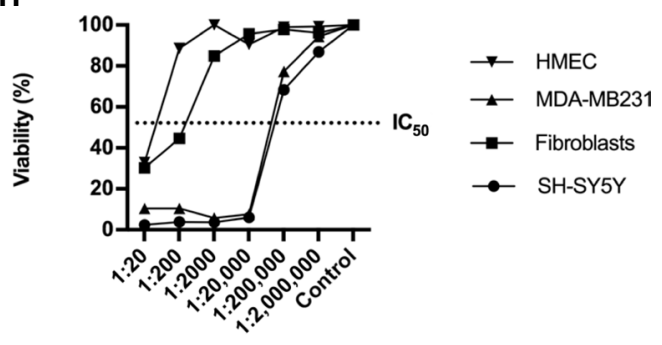

E
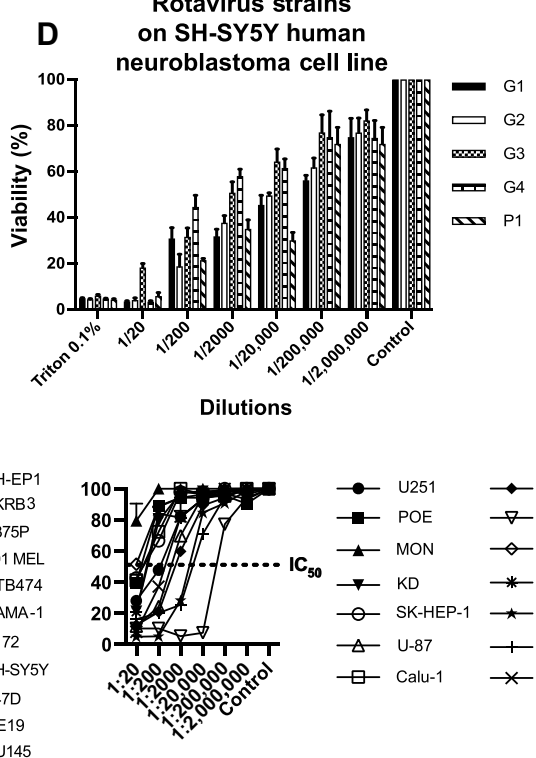

G
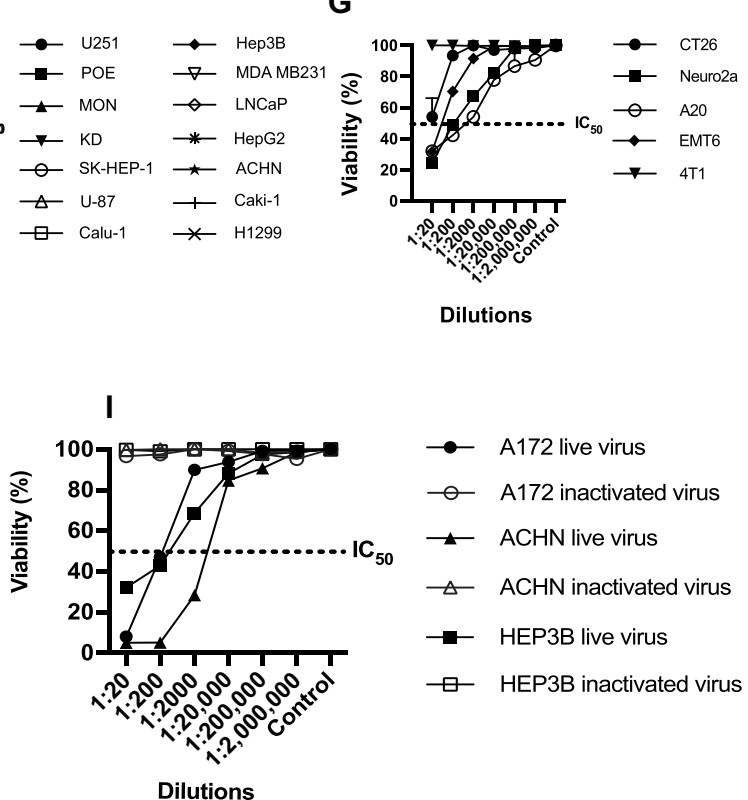
A

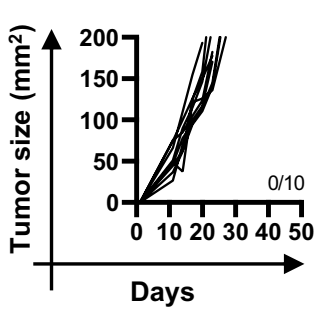

Pure rotavirus

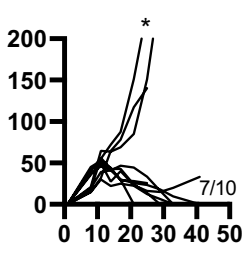

Rotavirus 1:10

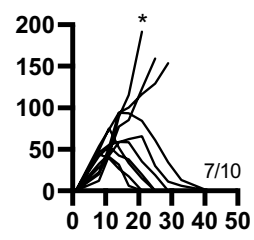

Rotavirus 1:100

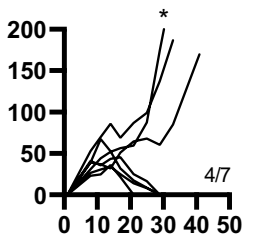

A20

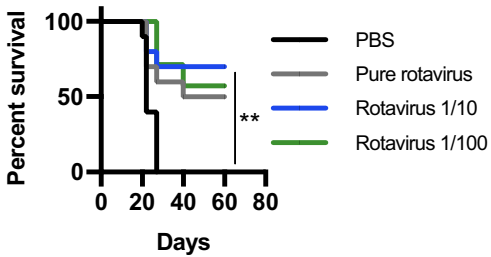

B

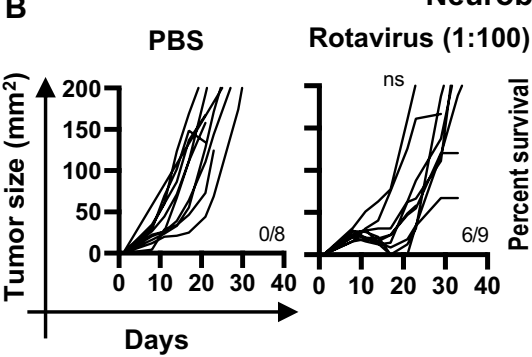

Neuroblastoma (Nxs2)

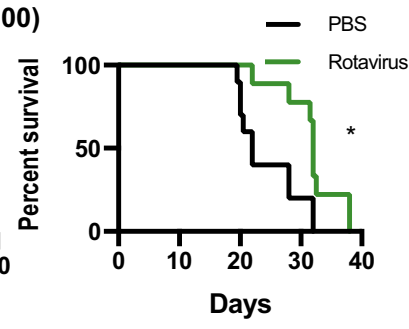

C

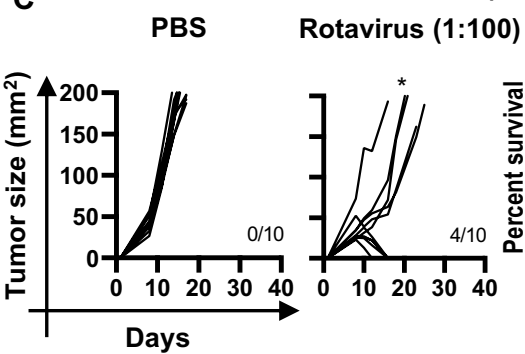

Neuroblastoma (Neuro2a)

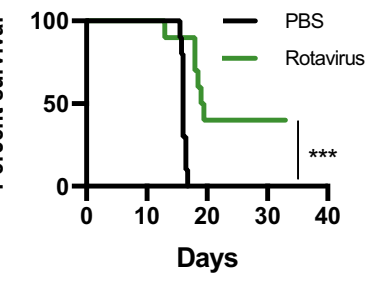

D Tumor-infiltrating immune cells upon IT rotavirus therapy

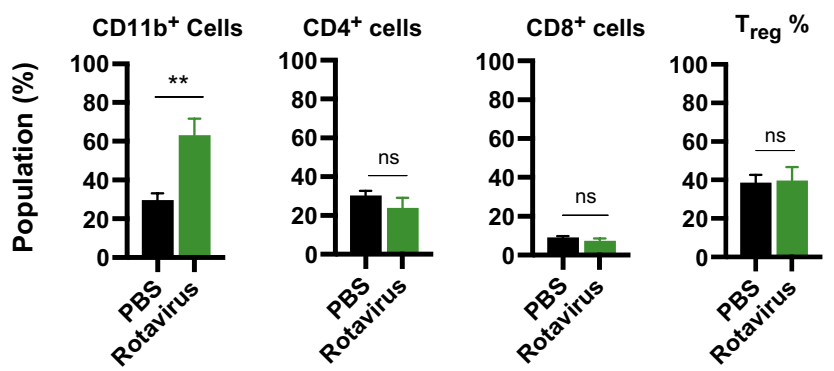

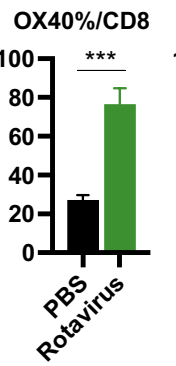

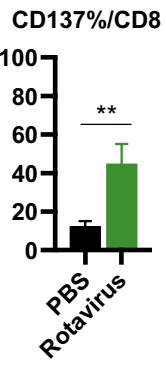

E

Rotavirus on human macrophage phenotype

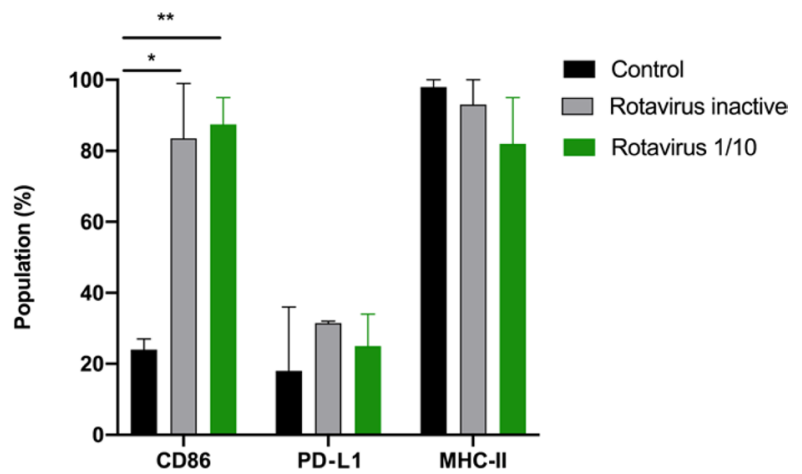

Fig. 3. In vitro oncolytic properties of rotavirus strains translate into in vivo immune activation and antitumor immunity. (A) Therapeutic activity of pure and diluted IT rotavirus strains against A20 B cell lymphoma tumors. Briefly, $5 \times 10^{6}$ tumor cells were injected subcutaneously on day 0 , three IT injections of $100 \mu$ l of pure rotavirus, or 1:10 and 1:100 dilutions were performed every 3 days on days 7, 10, and 13. Tumor sizes (length $\times$ width) were evaluated twice a week. $n=10$ mice per group; unpaired one-tailed $t$ test, ${ }^{*} P<0.05$; log-rank test for survival, ${ }^{* *} P=0.001$. Each group was compared to PBS-injected group. The therapeutic activity of $1: 100$ diluted IT rotavirus was also tested against two murine syngeneic neuroblastoma model NXS2 (B) ( $n=8$ or 9 mice per group; $5 \times 10^{6}$ tumor cells injected per mice) and Neuro2a (C) ( $n=10$ mice per group; $5 \times 10^{6}$ tumor cells injected per mice). Unpaired one-tailed $t$ tests; log-rank test for survival rate, ${ }^{*} P<0.05$ and ${ }^{* * *} P=0.0001$. (D) Tumor-infiltrating immune cells were analyzed by flow cytometry 24 hours after the first IT Rotavirus injection in the Neuro2a tumor model. Results are presented as a percentage of cells from the tumor-infiltrative $\mathrm{CD}_{4} 5^{+}$population, and $\mathrm{T}_{\text {regs }}$ were gated as Foxp $3^{+}$cell in the IT CD4 ${ }^{+}$population. Rotavirus-injected tumors were compared to PBS-injected tumor. Data as means $\pm \mathrm{SEM}, n=5$ mice per group; unpaired one-tailed $t$ tests, ${ }^{*} P<0.05$, ${ }^{* *} P<0.005$, and ${ }^{* * *} P<0.0005$. (E) Flow cytometry analysis of CD86, MHC-II, and PD-L1 expression on human PBMC-derived M0 macrophages after 96 hours of coculture with live and inactivated rotavirus (dilution, $1: 10$ ). Data as means \pm SEM, $n=2$; unpaired one-tailed $t$ test, ${ }^{*} P<0.05$ and ${ }^{* *} P<0.005$.

these $\mathrm{CD} 11 \mathrm{~b}^{+}$myeloid cells had an activated phenotype, expressing high costimulatory molecule CD86 compared to PBS-treated tumors, suggesting a strong inflammatory response to the IT rotavirus injection (Fig. 3D, left bottom). Although the frequency of $\mathrm{CD}^{+}$
T cell infiltrates remained stable, a highly significant proportion of these $\mathrm{CD}^{+} \mathrm{T}$ cells up-regulated activation markers such as OX40 $(50 \%)$ and CD137 (30\%) on their surface, suggesting an activation of tumor-infiltrative $\mathrm{CD} 8^{+} \mathrm{T}$ cells upon IT rotavirus therapy 
(Fig. 3D, middle bottom). The inhibitory immune checkpoint CTLA-4 was also strongly up-regulated at the cell surface of both $\mathrm{CD}^{+}$and $\mathrm{T}_{\text {regs }}$ (Fig. $3 \mathrm{D}$, right bottom).

We then confirmed the ability of rotavirus to activate human myeloid cells, determined by CD86 up-regulation. Human monocytederived macrophages from healthy donors strongly up-regulated membrane CD86 upon coculture with rotavirus (Fig. 3E). This up-regulation was maintained when macrophages were exposed to heat- and UV-inactivated rotavirus, suggesting that this effect could be due to pathogen-associated molecular patterns rather than relying on the ability of rotavirus to infect macrophages.

\section{Rotavirus induces immunogenic cell death and type I IFN pathways in cancer cells}

To further understand the IT immune response generated by IT rotavirus therapy and to explore its potential in nonpediatric cancer types, we evaluated the impact of rotavirus on the transcriptomic activity of A20 B cell lymphoma tumor cells and EMT6 breast carcinoma cells. We analyzed the differential expression of $770 \mathrm{im}-$ mune genes upon exposure of these tumor cells to rotavirus in vitro and found that 23 genes up-regulated in both cell lines, 2 genes down-regulated in both cell lines, and 5 discrepant genes $(3$ genes up-regulated in A20, which were down-regulated in EMT6, and 2 genes up-regulated in EMT6, which were down-regulated in A20) (table S1). Only the 23 genes commonly up-regulated by both cell lines were statistically associated with rotavirus exposure $(P=2.15 \times$ $10^{-8}$; table S2). Among these 23 genes commonly up-regulated in A20 and EMT6 tumor cells upon rotavirus treatment, we found genes such as Cxcl10, Cxcl11, Ifng1, Irf7, Ifit2, Ifi1, Ifi35, Ifi204, and $M x A$, all belonging to the type I IFN signaling pathway (Fig. 4A). We also found that the genes of cytosolic sensors of double-stranded RNAs (dsRNAs) such as Ifih1/MDA5, Tlr3, and $d d x 58 / R I G-I$ were commonly up-regulated by A20 and EMT6 cells upon treatment, suggesting a direct activation of these receptors by rotavirus, which belongs to the family of dsRNA viruses.

We confirmed the activation of the type I IFN pathway at the protein level by analyzing the expression of the IFN-inducible MxA protein by immunofluorescence. MxA was examined in A20 tumors treated with IT rotavirus compared to PBS control mice (Fig. 4B).

We also tested the ability of rotavirus to generate immunogenic cell death. We found that upon in vitro rotavirus exposure, both human and murine cancer cell lines generated an extracellular release of adenosine triphosphate (ATP) (Fig. 4C).

\section{IT rotavirus overcomes resistance and synergizes with anti-CTLA-4 and anti-PD-L1}

The up-regulation of CTLA-4 and CD86 on T cells and myeloid cells, respectively, provided the rationale for combination experiments between IT rotavirus and systemic anti-CTLA-4 antibodies. Although the Neuro2a neuroblastoma model was resistant to antiCTLA- 4 therapy and partially responsive to rotavirus monotherapy (Fig. 3C), we found that the combination of IT rotavirus together with systemic anti-CTLA-4 was highly synergistic with a $100 \%$ complete response rate with no relapse (Fig. 5A). Similarly, 100\% complete tumor regressions were also observed in the A20 B cell lymphoma model (Fig. 5B) with the combination, whereas only 50 to $70 \%$ of tumor rejections were observed with IT rotavirus alone or 10 to $20 \%$ with systemic anti-CTLA- 4 single agent. The IT delivery of rotavirus was required to obtain the synergy with anti-CTLA-4.
In the A20 B cell lymphoma model, a systemic delivery of rotavirus had very little antitumor effects and did not synergize with systemic anti-CTLA-4 (Fig. 5C). We also confirmed the synergistic efficacy and durability of this combinatorial therapy in adult tumor types such breast mammary carcinoma (EMT6) (Fig. 5D) and colon carcinoma (CT26) (Fig. 5E) syngeneic mice tumor models.

We confirmed in the Neuro2a and A20 tumor models that this synergy was still true when working with commercial rotavirus vaccines rather than the more concentrated rotavirus strains. We observed a synergistic effect of rotavirus vaccine with anti-CTLA-4 in the Neuro2a neuroblastoma model with $60 \%$ complete tumor regressions (Fig. 5F) and in the A20 B cell lymphoma model with $70 \%$ complete tumor regressions (Fig. 5G).

Because of the current clinical development of anti-PD-(L)1 antibodies in adult oncology and because PD-L1 was one of the top genes up-regulated by rotavirus on cancer cells (Fig. 4A), we also tested the synergistic effects of IT rotavirus and systemic anti-PD-L1 combination therapy in the A20 lymphoma model and found again a strong synergy with a $100 \%$ cure rate (Fig. $5 \mathrm{H}$ ).

\section{The in vivo therapeutic effects of IT rotavirus rely on a functional immune system}

To discriminate between the direct oncolytic antitumoral effects of rotavirus and its immune-mediated effects, we tested the IT rotavirus therapy in NOD scid gamma (NSG) immunodeficient mice bearing Neuro2a neuroblastoma tumors. The antitumor effects were abolished in NSG mice without any complete tumor rejection (Fig. 6A). To more specifically define the contribution of immune subsets, we depleted $\mathrm{CD} 4^{+} \mathrm{T}$ cells, $\mathrm{CD} 8^{+} \mathrm{T}$ cells, or natural killer (NK) cells in Balb/c mice transplanted with the A20 murine lymphoma. We observed that in the $\mathrm{CD}^{+} \mathrm{T}$ cell-depleted mice, the antitumoral effect of the rotavirus monotherapy or the combination with anti-CTLA-4 was abolished (Fig. 6B). In addition, the depletion of $\mathrm{CD}^{+} \mathrm{T}$ cells and NK cells impaired the therapeutic response to IT rotavirus. The absolute requirement of $\mathrm{CD} 8^{+} \mathrm{T}$ cells and the necessity to also have $\mathrm{CD} 4^{+} \mathrm{T}$ cells and NK cells were confirmed in the setting of IT rotavirus in combination with intraperitoneal (IP) anti-CTLA-4 (Fig. 6C).

To test whether this involvement of the $\mathrm{T}$ cell adaptive immunity was also generating a long-term memory antitumor immune response, we took mice cured from their A20 lymphoma or Neuro2a neuroblastoma tumors by the IT rotavirus + IP anti-CTLA- 4 combination therapy and reinjected them with the same tumor cells. We observed protection upon rechallenge, demonstrating the induction of an adaptive antitumor immune memory response in cured mice (Fig. 6D). In addition, to test whether this long-term protection was tumor specific, we took other Balb/c mice cured from A20 lymphoma tumors by the IT rotavirus + IP anti-CTLA- 4 combination therapy and rechallenged them with both A20 lymphoma cells and irrelevant $4 \mathrm{~T} 1$ breast cancer carcinoma cells in two separate flanks. The 4T1 breast carcinoma tumors developed in these cured mice, whereas the A20 lymphoma tumors did not, illustrating the specificity of the antitumor immune response generated upon the combination therapy (fig. 6E).

Then, to better assess the $\mathrm{T}$ cell memory antitumor response induced by the IP anti-CTLA-4 + IT rotavirus combination, we took splenocytes from A20 lymphoma and Neuro2a neuroblastoma cured mice and exposed them in vitro to the respective tumor cells. 
A

\begin{tabular}{|c|c|c|c|c|c|c|}
\hline & \multirow[b]{2}{*}{ Gene } & \multirow[b]{2}{*}{ aka } & \multicolumn{2}{|c|}{$\log _{2}$ fold change } & \multicolumn{2}{|c|}{$P$ value } \\
\hline & & & EMT6 & $\mathrm{A} 20$ & EMT6 & A20 \\
\hline 1 & Cxcl10 & IP10 (Interferon- $\gamma$-inducible protein 10) & 8.32 & 4.94 & $0.00 \mathrm{E}+00$ & $1.90 \mathrm{E}-213$ \\
\hline 2 & Cxcl11 & ITAC (interferon-inducible T cell $\alpha$ chemoattractant) & 7.13 & 1.18 & $5.90 E-300$ & $2.10 E-04$ \\
\hline 3 & $\mid f n b 1$ & Interferon $\beta 1$ & 6.29 & 3.76 & $0.00 \mathrm{E}+00$ & $8.80 \mathrm{E}-77$ \\
\hline 4 & Ccl5 & RANTES & 6.17 & 6.28 & $0.00 E+00$ & $1.10 \mathrm{E}-197$ \\
\hline 5 & $\operatorname{lnf7}$ & Interferon regulatory factor 7 & 5.73 & 5.98 & $1.20 \mathrm{E}-182$ & $5.40 \mathrm{E}-300$ \\
\hline 6 & CD274 & PD-L1 & 5.56 & 2.53 & $0.00 E+00$ & $8.00 \mathrm{E}-140$ \\
\hline 7 & Mx1 & Interferon-induced GTP-binding protein (MxA) & 4.79 & 1.67 & $0.00 E+00$ & $7.10 \mathrm{E}-44$ \\
\hline 8 & Bst2 & CD317, TETHERIN & 4.61 & 1.41 & $0.00 \mathrm{E}+00$ & $7.70 \mathrm{E}-51$ \\
\hline 9 & Tnfsf 10 & TRAIL (TNF-related apoptosis-inducing ligand) & 4.5 & 1.28 & $1.20 \mathrm{E}-178$ & $2.20 \mathrm{E}-05$ \\
\hline 10 & Ccr/2 & C-C chemokine receptor-like 2 & 4.34 & 5.16 & $3.60 \mathrm{E}-101$ & $5.20 E-99$ \\
\hline 11 & Iffih1 & MDA5 (melanoma differentiation-associated protein 5) & 4.28 & 4.19 & $0.00 E+00$ & $3.00 E-295$ \\
\hline 12 & Ptpn22 & Protein tyrosine phosphatase, nonreceptor type 22 & 4.27 & 2.32 & $6.10 E-255$ & $1.10 \mathrm{E}-12$ \\
\hline 13 & Ifit2 & Interferon-induced protein with tetratricopeptide repeats 2 & 3.99 & 2.78 & $0.00 \mathrm{E}+00$ & $6.50 \mathrm{E}-109$ \\
\hline 14 & $\operatorname{Irgm1}$ & Interferon-inducible protein 1 (IFI1) & 3.79 & 4.49 & $0.00 E+00$ & $3.50 \mathrm{E}-267$ \\
\hline 15 & Stat1 & Signal transducer and activator of transcription 1 & 3.72 & 3.26 & $0.00 E+00$ & $9.70 \mathrm{E}-211$ \\
\hline 16 & T/r3 & Toll-like receptor 3 (CD283) & 3.49 & 1.27 & $0.00 \mathrm{E}+00$ & $3.00 \mathrm{E}-05$ \\
\hline 17 & Iffi35 & Interferon induced protein 35 & 3.04 & 1.45 & $0.00 E+00$ & $9.10 E-56$ \\
\hline 18 & $D d \times 58$ & RIG-I (retinoic acid-inducible gene I) & 2.56 & 5.28 & $3.50 E-255$ & $1.60 \mathrm{E}-295$ \\
\hline 19 & Ifi204 & Interferon-activable protein 204 & 2.44 & 1.99 & $6.40 \mathrm{E}-288$ & $2.50 \mathrm{E}-10$ \\
\hline 20 & Cd80 & B7-1 & 2.08 & 1.31 & $1.70 \mathrm{E}-35$ & $5.60 \mathrm{E}-08$ \\
\hline 21 & Aicda & Activation-induced cytidine deaminase & 1.86 & 1.89 & $8.00 \mathrm{E}-08$ & $2.10 E-58$ \\
\hline 22 & $\mathrm{Pml}$ & TRIM19 (tripartite motif containing 19) & 1.81 & 2.34 & $1.80 \mathrm{E}-145$ & $1.40 \mathrm{E}-107$ \\
\hline 23 & Tap1 & Transporter associated with antigen processing 1 & 1.57 & 1.1 & $1.00 \mathrm{E}-92$ & $2.20 \mathrm{E}-30$ \\
\hline
\end{tabular}

B

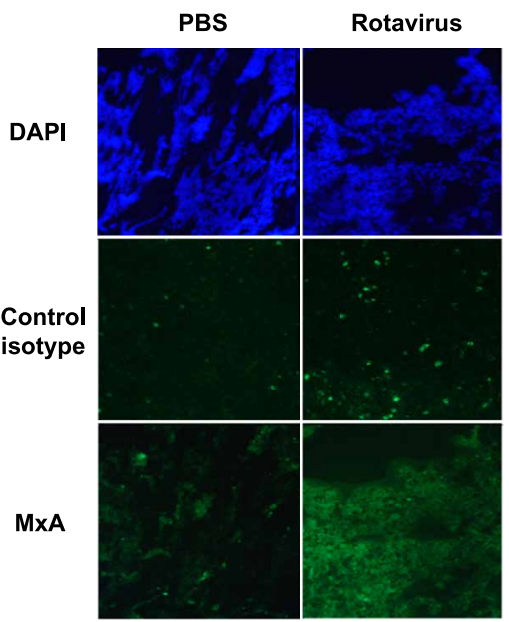

C

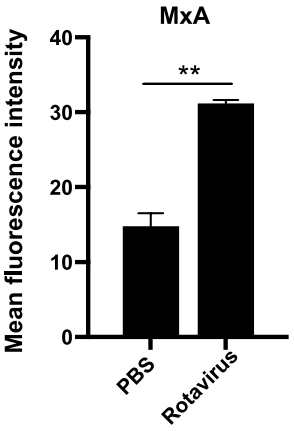

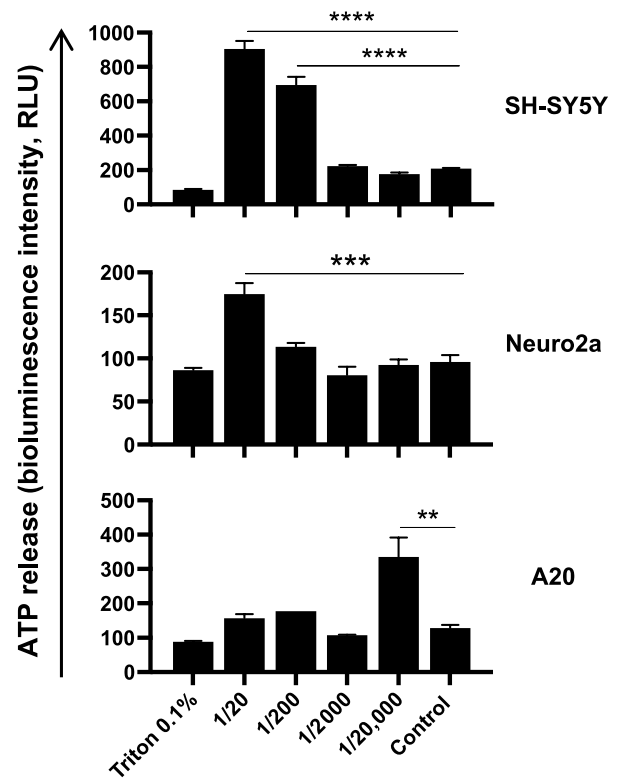

Fig. 4. Rotavirus induces the type I IFN pathway and release of ATP by tumor cells. (A) List of the 23 shared genes commonly up-regulated by A20 and EMT6 cancer

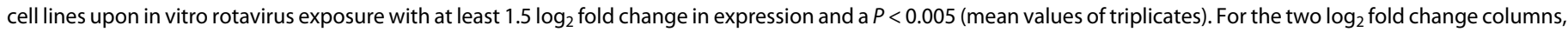
a gradient from white to red allows identification of the genes with the weakest (white) to the strongest (red) up-regulations. Genes highlighted in gray are in common with the list of genes up-regulated in A20 upon exposure with inactivated rotavirus (see Fig. 7D). (B) Pictures of immunofluorescence staining (magnification, $\times 20$ ) with anti-MxA-specific monoclonal antibodies and secondary detection on A20 tumors harvested from Balb/c mice after either IT rotavirus or IT PBS treatment. Staining was performed on frozen tumor sections. An isotype control was used as a negative control for MxA detection (in green) after DAPI (4',6-diamidino-2-phenylindole) counterstaining (in blue). The means ( \pm SEM) of immunofluorescence intensity as measured by the ImageJ software are presented in the right panel. Data from $n=2$ mice in each group with three tumor sections. Unpaired one-tailed $t$ test, ${ }^{* *} P=0.005$. (C) ATP release in the cell culture supernatant upon several dilutions of rotavirus exposure on human (SH-SY5Y neuroblastoma) or murine (Neuro2a neuroblastoma and A20 B-cell lymphoma) tumor cell lines. Measurement performed by luminescence assay using CellTiter-Glo Luminescent Cell Viability Assay kit 48 hours after incubation with different dilutions of rotavirus. Results are reported as RLU intensity corresponding to relative ATP release intensity. Data as means $\pm \mathrm{SEM}, n=3$ wells per dilution; one-way ANOVA test, ${ }^{* * *} P<0.0001,{ }^{* * *} P<0.0005$, and ${ }^{* *} P<0.005$. 
Fig. 5. Intratumoral rotavirus synergizes with and overcomes the resistance to immune checkpointtargeted therapies. Tumor growth and survival rates of mice treated with three IT injections of $100 \mu$ l of rotavirus strains (1:100 dilution) and/or four IP injections of $200 \mu \mathrm{g}$ of $\alpha \mathrm{CTLA}-4$ with 3-day intervals in (A) the Neuro2a neuroblastoma and (B) the A20 B cell lymphoma tumor models. $n=10$ mice per group and each group compared to PBS; unpaired one-tailed $t$ test comparing the mean tumor sizes of each group, ${ }^{*} P<0.05$ and ${ }^{* *} P<0.005$; survival rate (log-rank test), ****P $P<0.0001$. (C) Survival of mice treated with systemic anti-CTLA-4 together with either IT or systemic rotavirus in the A20 B cell lymphoma model. $n=8$ to 9 mice per group; survival rate (log-rank test), ${ }^{* *} P=0.001$ (D) Tumor growth and survival rates in the EMT6 murine breast mammary carcinoma and (E) the CT26 murine colorectal tumor models. Same protocol as described in $(A)$ and $(B)$; means $\pm S E M$, $n=9$ to 10 mice per group Combinations of IT rotavirus vaccine and/or IP $\alpha C T L A-4$ in the Neuro2a neuroblastoma (F) and the A20 B cell lymphoma models (G). Same protocol as above; means \pm SEM, $n=9$ to 10 mice per group; unpaired one-tailed $t$ test, * $P<0.05$. Combination group (rotavirus vaccine $+\alpha$ CTLA- 4 ) is compared to PBS group. (H) Tumor growth and survival rates of IT rotavirus and/or IP $\alpha P D-L 1$ in the A20 B cell lymphoma model. Same protocol as above; means \pm SEM, $n=7$ to 8 mice per group; unpaired one-tailed $t$ test, ${ }^{*} P<0.05$. Combination group (rotavirus $+\alpha$ PD-L1) is compared to PBS group.
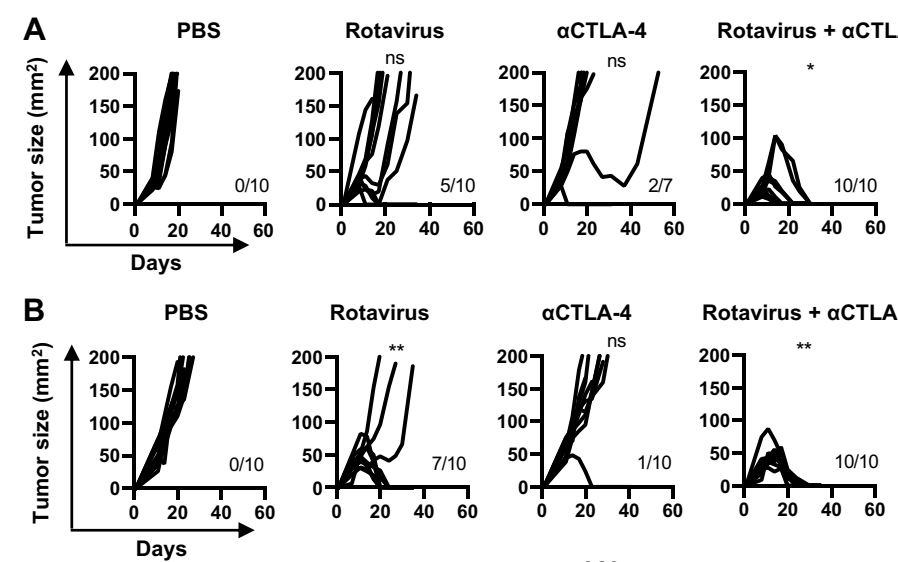

C
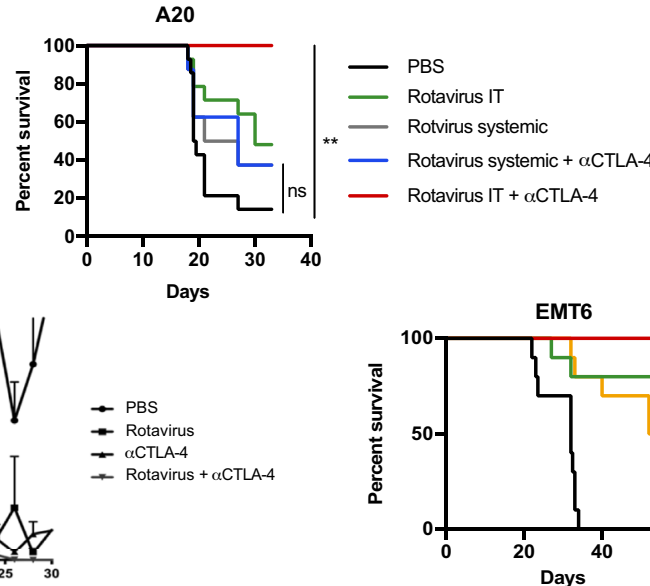

D
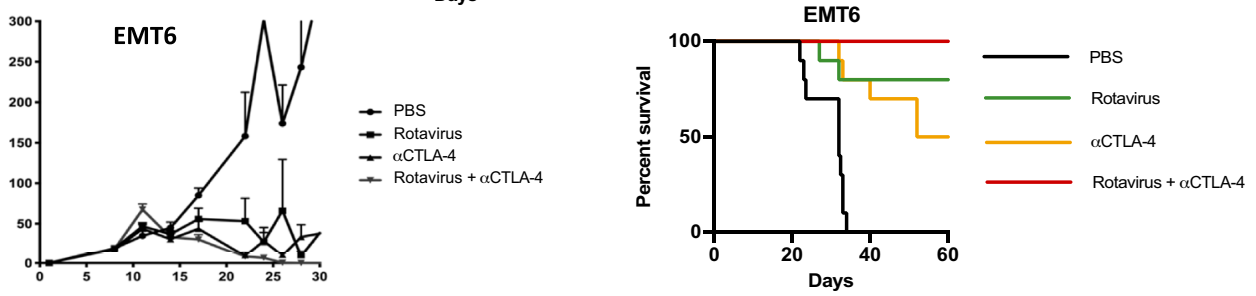

E
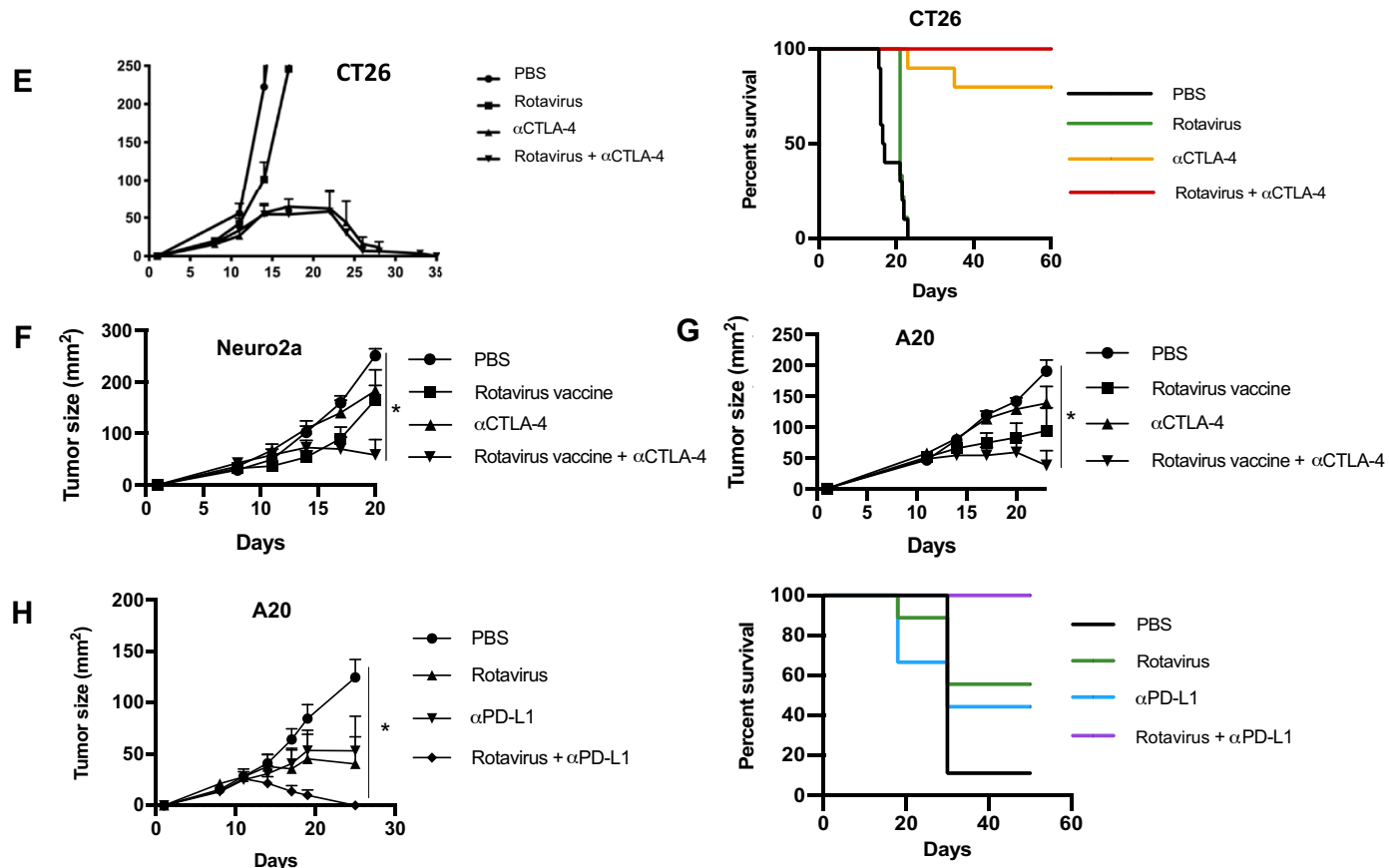

After 4 days, $\mathrm{CD}^{+} \mathrm{T}$ cells were stained for intracellular IFN- $\gamma$ and surface CD137 and OX40 activation markers and analyzed by flow cytometry. We observed that $\mathrm{CD}^{+} \mathrm{T}$ cells from splenocytes of mice cured by the IT rotavirus + IP anti-CTLA- 4 combination therapy produced two to three times higher (5 to 15\%) intracellular IFN- $\gamma$ compared to naive mice and expressed up-regulated surface 
A

NSG mice (Neuro2a)

PBS

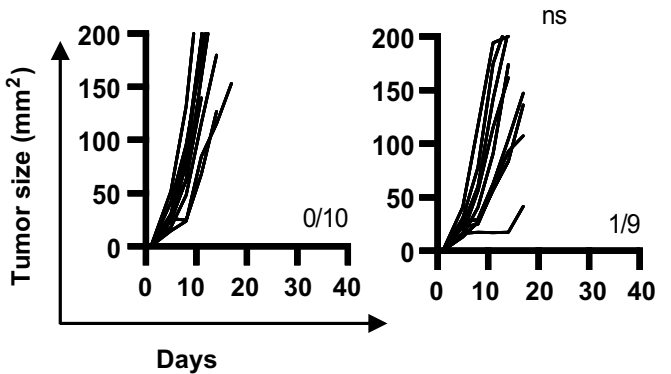

B

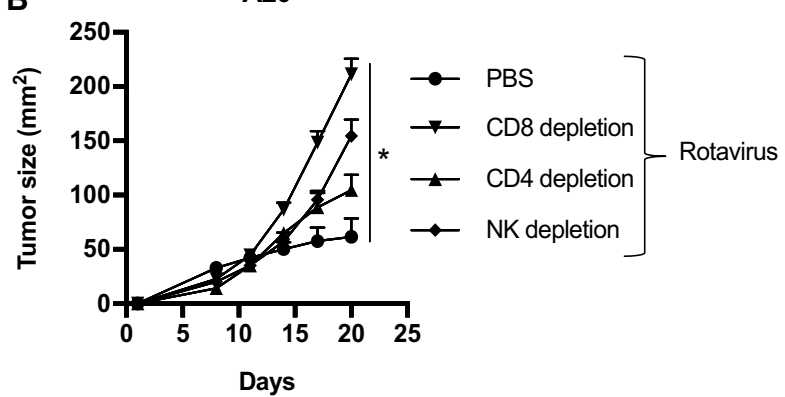

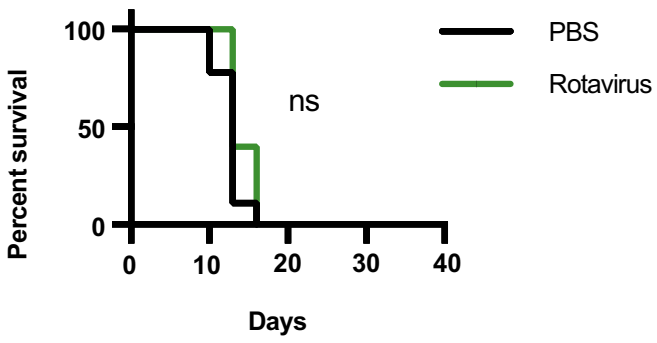

C
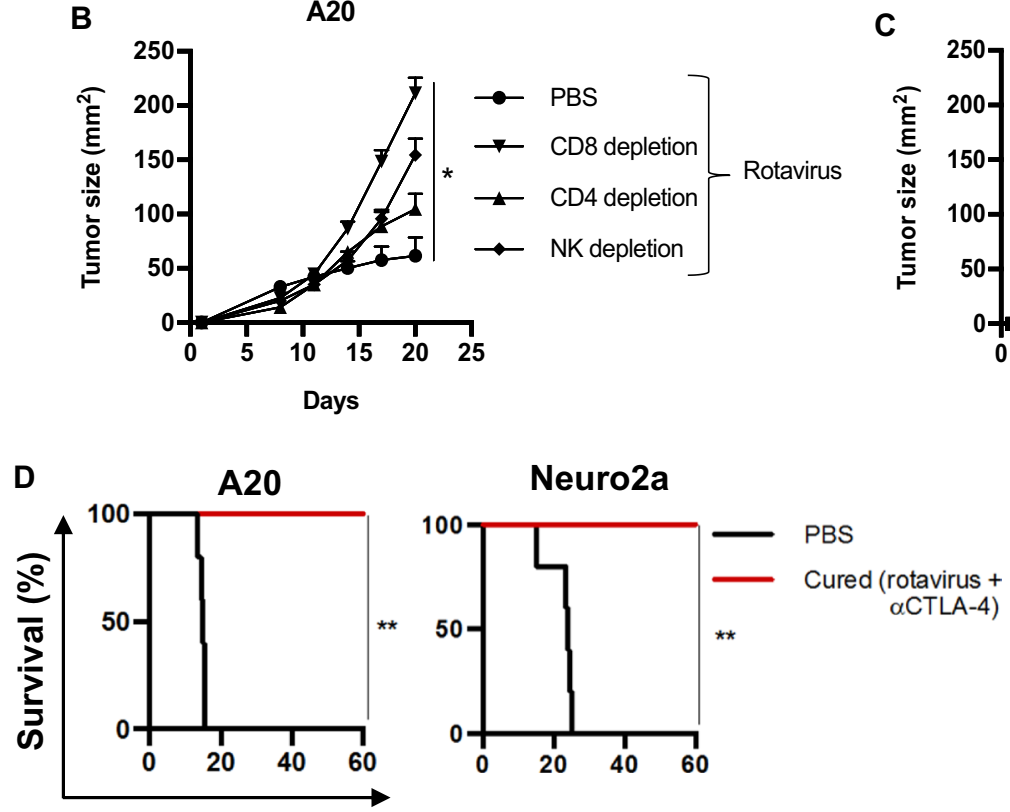

Days

F

A20

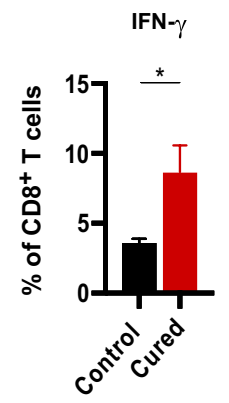

Ox40

CD137
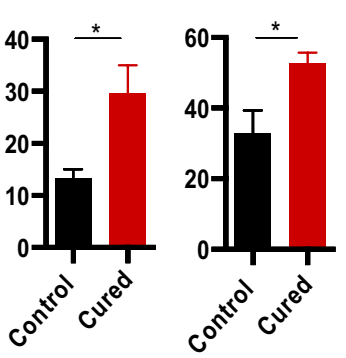

G

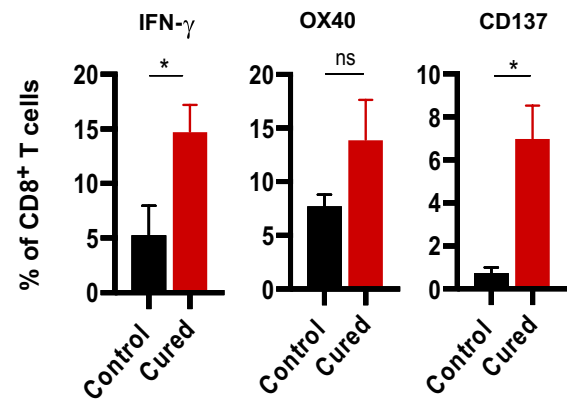

Fig. 6. Intratumoral rotavirus therapy in combination with anti-CTLA-4 generates a tumor-specific CD8 ${ }^{+} \mathbf{T}$ cell immune response. (A) In vivo antitumor effects of three injections of 1:100 rotavirus strain into Neuro2a tumors growing in NSG immunodeficient mice. Tumor growth (left) and mice survival rates (right). $n=9$ to 10 mice per group; unpaired one-tailed $t$ test. A20 tumor growth after CD8, CD4, or NK cell depletions in mice treated with IT rotavirus alone (B) and IT rotavirus + IP $\alpha$ CTLA-4 (C). Same therapeutic protocol as described before; means \pm SEM, $n=10$ mice per group; unpaired one-tailed $t$ test, ${ }^{*} P<0.05$. Each group is compared to control group. (D) Survival rates of mice cured from A20 lymphoma (left) and Neuro2a neuroblastoma (right) after rechallenge with the same tumor. $n=5$ mice per group; log-rank test, ${ }^{* *} P<0.005$. (E) Tumor growth in mice cured from A20 lymphoma and rechallenged with both A20 lymphoma and 4T1 mammary carcinoma cells. Means \pm SEM, $n=3$ mice per group; unpaired one-tailed $t$ test, ${ }^{*} P<0.05$. Intracellular IFN- $\gamma$ and membrane activation markers on $C D 8^{+} \mathrm{T}$ cells from cured versus control mice cocultured in vitro with $\mathrm{A} 20$ lymphoma cells (F) or Neuro2a neuroblastoma cells (G). Briefly, splenocytes from mice cured of an A20 lymphoma or Neuro2a tumor by IT rotavirus + IP $\alpha$ CTLA-4 and splenocytes from control mice bearing A20 lymphoma tumors or Neuro2a tumors but treated with IT PBS were cocultured with the relevant A20/Neuro2a tumor cell line for 4 days. Then, CD8 T cells were stained for intracellular IFN- $\gamma$ and surface activation markers. Means \pm SEM, $n=3$ mice per group; unpaired one-tailed $t$ test, ${ }^{*} P<0.05$. 

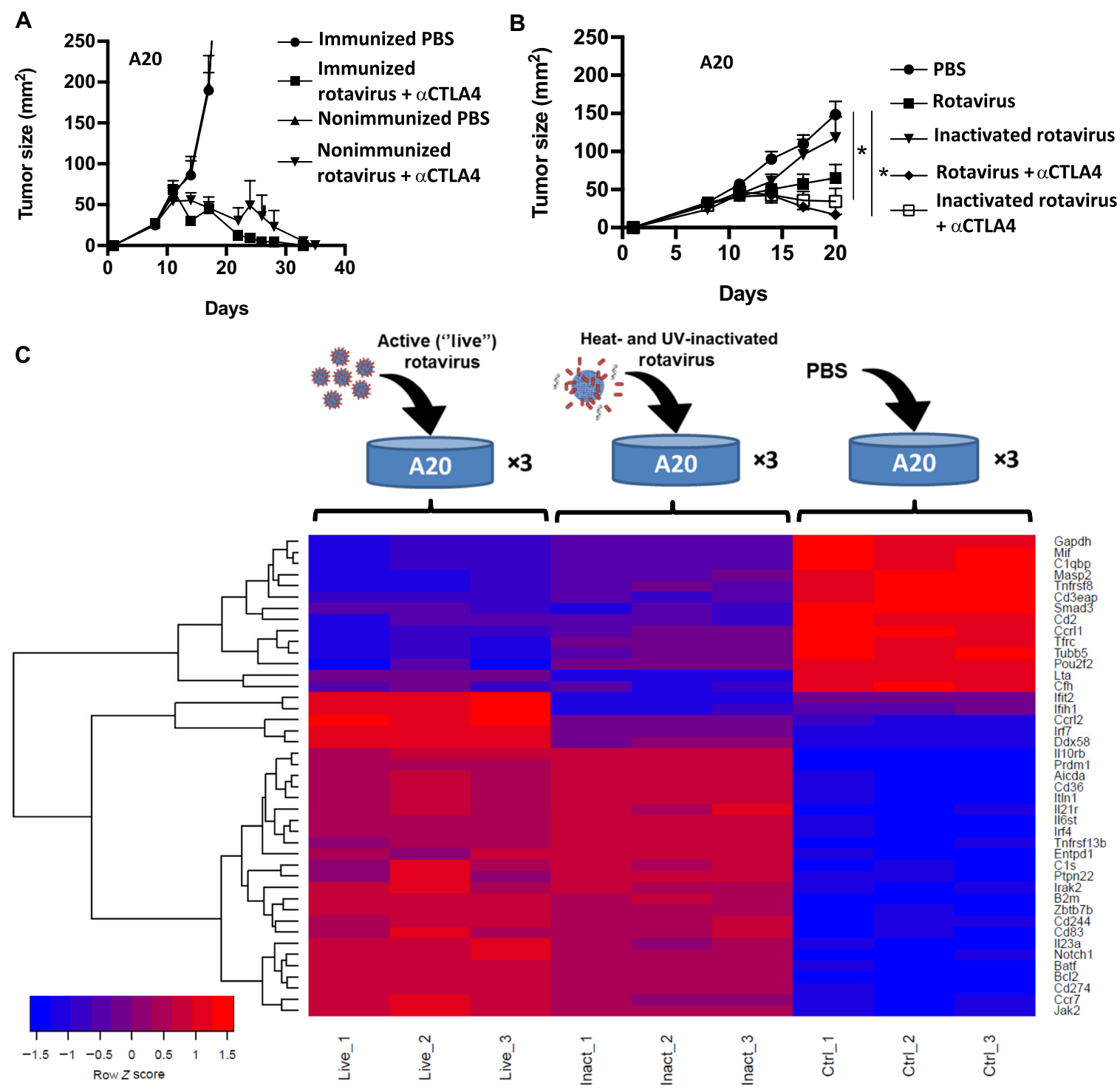

D

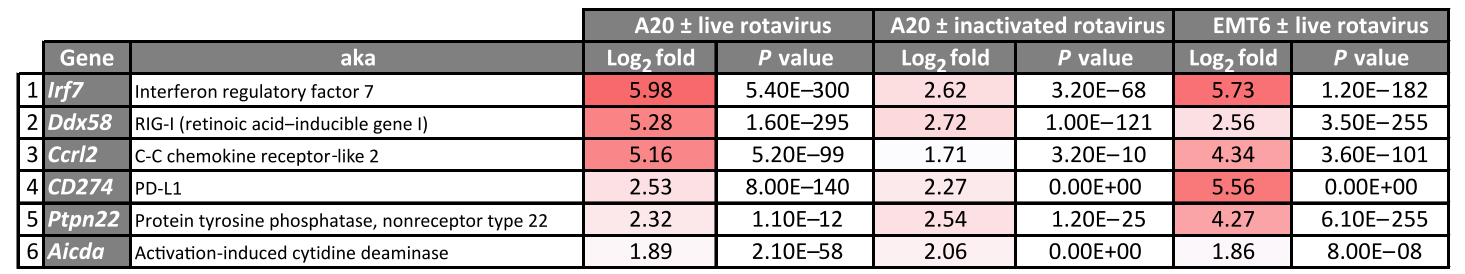

Fig. 7. Intrinsic rotavirus components are driving the proinflammatory features necessary for the synergy with anti-CTLA-4. (A) Tumor growth of A20 tumors in mice preimmunized or not with oral rotavirus vaccine and treated with the combination of IT rotavirus and IP $\alpha C T L A-4$. Same therapeutic protocol as described before; means \pm SEM, $n=10$ mice per group. (B) Tumor growth of A20 tumors upon treatment with IT live or inactivated rotavirus, alone or in combination with $\alpha C T L A-4$. Same therapeutic protocol as described before; means $\pm \mathrm{SEM}, n=9$ to 10 mice per group; unpaired one-tailed $t$ test, ${ }^{*} P<0.05$. Each group is compared to the PBS group. (C) Heatmap representing the list of genes commonly differentially expressed (i.e., up-regulated or down-regulated) by A20 tumor cells upon incubation with active (live) or inactivated ("Inact") virus or PBS ("Ctrl"); genes selected on the basis of $\mid \log _{2}$ fold change of $\geq 1$ and $P \leq 0.005$; experiment performed was in triplicate; each triplicate data are depicted. (D) List of the six genes commonly up-regulated by A20 tumor cells exposed to active (live) or inactivated rotavirus and by EMT6 tumor cells exposed to live rotavirus as compared to media. For each gene, the $\log _{2}$ fold change value and the $P$ value are provided. A gradient of colors from white to red has been attributed to the $\log _{2}$ fold change values from lowest to highest values, respectively, under all conditions. 
activation markers such as CD137 and OX40 compared to control mice in both tumor models (Fig. 6, F and G).

\section{The ability to overcome the resistance to anti-CTLA-4 is} associated with the up-regulation of specific immune genes

We then tested whether a preimmunization against the rotavirus would prevent the ability of IT rotavirus to synergize with antiCTLA-4. Because Rotateq is originally an orally administered vaccine, we preimmunized Balb/c mice with an oral administration of the Rotateq vaccine two times (days -15 and -7 ) before the tumor challenge with A20 B cell lymphoma cells. We found the same synergistic effects of the IT rotavirus + IP anti-CTLA-4 combination therapy in immunized and nonimmunized mice (Fig. 7A).

Because preexisting immunity against the virus did not prevent therapeutic benefit, we hypothesized that the immunostimulatory viral components (rather than the ability to infect cells and replicate) were possibly sufficient to overcome the resistance to antiCTLA-4. To test this hypothesis, we inactivated the rotavirus with both thermal and UV exposure to compare the activity of IT inactivated rotavirus to IT active ("live") rotavirus. IT inactivated rotavirus had no antitumoral efficacy when used as a monotherapy, as opposed to active rotavirus (Fig. 7B). However, unexpectedly, IT inactivated rotavirus was as efficient as IT active rotavirus to synergize with and overcome the resistance to anti-CTLA-4 (Fig. 7B).

To better understand the immunostimulatory properties of inactivated rotavirus, we exposed A20 tumor cells to either active or inactivated rotavirus for 24 hours and performed a transcriptomic analysis. We compared the transcriptomic impact of active (live) rotavirus and inactivated rotavirus and identified a list of genes that are differentially expressed (either up- or down-regulated) under the two conditions (table S3 and fig. S2).

Because inactivated rotavirus behaved the same as active rotavirus when used in combination with anti-CTLA-4, we focused on the genes that were commonly regulated by the cancer cells by both states of rotavirus (fig. S3). We identified the list of genes represented in the heatmap in Fig. 7C. We found that the inactivated rotavirus was still able to induce a strong expression of the type I IFN pathway: interferon regulatory factor 4 (IRF4) and IRF7 were still among the top up-regulated genes with $\log _{2}$ fold changes above 2 with inactivated rotavirus. Among the dsRNA sensors, which could trigger such up-regulation of IRFs and which were commonly up-regulated in A20 and EMT6 by active (live) rotavirus in previous experiments, only the ddx58/RIG-I gene was also up-regulated by the inactivated rotavirus in the A20 cells; Ifih1/MDA5 was down-regulated by inactivated rotavirus, and TLR3 remained steady.

Because the IT rotavirus + IP anti-CTLA-4 was also curative in the EMT6 mammary carcinoma model, we sought to identify the common genes differentially expressed in these cells under the same conditions. We compared the lists of genes differentially expressed in the EMT6 cancer cells after rotavirus exposure with the list of genes commonly regulated by active and inactive rotavirus in A20 cancer cells. We found only six genes that were commonly up-regulated by EMT6 cells with active rotavirus, A20 cells with inactive rotavirus, and A20 cells with inactivated rotavirus (Fig. 7D).

We also examined the transcriptomic impact of IT rotavirus in vivo by collecting A20 tumors 48 hours after IT rotavirus therapy. We identified a list of genes commonly regulated by active (live) and inactivated rotavirus (fig. S4 and table S4). We found that CD86 was only up-regulated upon active (live) rotavirus exposure $\left(\log _{2}\right.$ fold change, 1.56) but not with inactivated rotavirus. As shown above, CD80 (also known as B7.1), another costimulatory signal at the immune synapse between antigen-presenting cells and $\mathrm{T}$ cell, was up-regulated in vitro by both EMT6 and A20 upon rotavirus exposure but not with inactivated rotavirus on A20 cells both in vivo and in vitro (Fig. 7C and table S4, respectively). Together, these data suggest that active (live) rotavirus can up-regulate both CD86 and CD80 in murine tumors but not with inactive rotavirus.

We also found that $C D 163$, a scavenger molecule, was one of the top genes up-regulated in vivo by A20 tumors after 48 hours of IT rotavirus and this gene was commonly up-regulated upon active and inactivated IT rotavirus therapy. We found this effect at the protein level on human myeloid cells with both active and inactivated rotavirus: Monocytes and in vitro-differentiated human M1 macrophages showed up-regulation of CD163 (fig. S5). M2 macrophages were constitutively $\mathrm{CD} 163^{+}$, and no variation could therefore be seen upon rotavirus exposure. We concluded that rotavirus only had an impact in vitro on CD163 expression on monocytes and M1 subsets of myeloid cells.

Among the genes commonly up-regulated in vivo by both active (live) and inactivated rotavirus, we could confirm the activation of numerous genes from the type I IFN pathway such as Ifna1, Ifna2, $M x 1$, and IfnbI and the up-regulation of the IFN- $\gamma$ (Ifng) gene. In addition, a number of genes from effector $\mathrm{T}$ cells were up-regulated such as interleukin-25 (IL-25), IL-9, IL-17, Tbx21 (also known as Tbet), and retinoic acid binding-related orphan receptor $\mathrm{c}(\mathrm{ROR})$ ). Together, the fact that common immune genes could be found to be up-regulated upon IT rotavirus therapy, both in vitro and in vivo, with both active and inactivated rotavirus, illustrates the ability of rotavirus and its components to trigger a coordinated antitumor immune response, which is enhanced by systemic anti-CTLA-4 therapy.

\section{IT rotavirus generates abscopal and durable tumor-specific immunity}

To assess whether the IT rotavirus + IP anti-CTLA-4 combination therapy could also induce an antitumor effect on distant noninjected tumors (abscopal effect), we set up a double-tumor mouse model by injecting tumor cells on both flanks of the mice (Fig. 8A). Rotavirus was injected in one of the two tumor sites, and anti-CTLA-4 antibody was injected systemically (intraperitoneally) after the same protocol as previously described. Despite the aggressive features of the double-tumor models, the combination could cure $100 \%$ of the mice with complete regressions of both injected and noninjected tumors, both in the A20 lymphoma model (Fig. 8B) and in the Neuro2a neuroblastoma model (Fig. 8C). We studied the effects of this combination therapy on the immune infiltrating cells at the injected and distant tumors.

Although Neuro2a tumors contained more myeloid cells at baseline than A20 tumors (Fig. 8, D and E, respectively, left), we observed a similar impact on both tumor models of IT rotavirus (1:100) injections (analyzed 24 hours after the second IT injection): (i) Myeloid cells were activated (as shown by CD86 up-regulation) in both the injected and distant (noninjected) tumors with and without anti-CTLA-4 (Fig. 8, D and E, middle left); (ii) $\mathrm{CD}^{+}$ $T$ cells increased in numbers both in injected and distant tumors particularly in the Neuro2a model after combination therapy (Fig. 8, D and E, middle right); and (iii) high CD8 $\mathrm{T}$ cell activation was observed with OX40 up-regulation in both models, both the injected and distant tumors (Fig. 8, D and E, right). 
Fig. 8. IT rotavirus with systemic anti-CTLA-4 generates a systemic antitumor immunity, which eradicates distant, noninjected established tumors. (A) Picture illustrating the twotumor mouse model. Briefly, mice were injected with either A20 or Neuro2a tumor cells on both flanks. IT therapy was performed in only one of the two tumors and started when both tumors were established ( day 7). Growth of injected (left) or uninjected ("distant"; middle) tumors and survival (right) of mice treated with IT rotavirus in one tumor " $\mathrm{in}$ jected") and IP anti-CTLA-4 in the A20 (B) and Neuro2a (C) models. $n=10$ mice per group; survival rate (log-rank test), ${ }^{* * *} P<0.0001$ and ${ }^{* * *} P=0.0004$. (D and $\mathbf{E}$ ) Proportion and phenotype of tumor-infiltrating immune cells from injected and noninjected (distant) tumors upon IT rotavirus in one tumor (injected) and IP anti-CTLA-4. Flow cytometry analysis; tumors were excised 24 hours after the second IT injection of rotavirus. $\mathrm{CD} 11 \mathrm{~b}$ and $\mathrm{CD} 8$ are gated from $\mathrm{CD}_{4} 5^{+}$cells for OX40 and CD86 marker analysis; means $\pm \mathrm{SEM}, n=3$ mice per group; unpaired onetailed $t$ test, ${ }^{*} P<0.05$ and ${ }^{* *} P<0.005$. Each group is compared to PBS.

\section{DISCUSSION}

Immune checkpointtargeted antibodies are currently revolutionizing cancer treatment. However, most of the patients remain resistant to these immunotherapies. This study was designed to evaluate clinical-grade strategies to overcome such resistance. We previously showed that the IT injection of PRR agonists can induce an antitumor immunostimulation that can synergize with ICB monoclonal antibodies (mAbs) (26). Commercially available anti-infectious disease vaccines represent a potential alternative source of PRR agonists, notably in the context

B

C

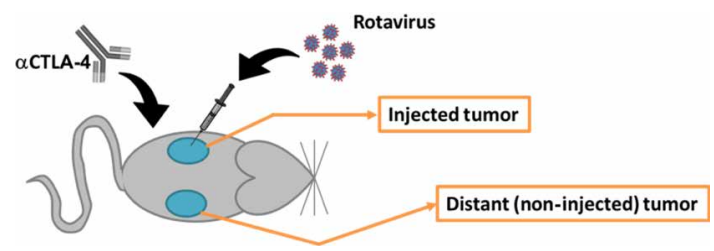

A20
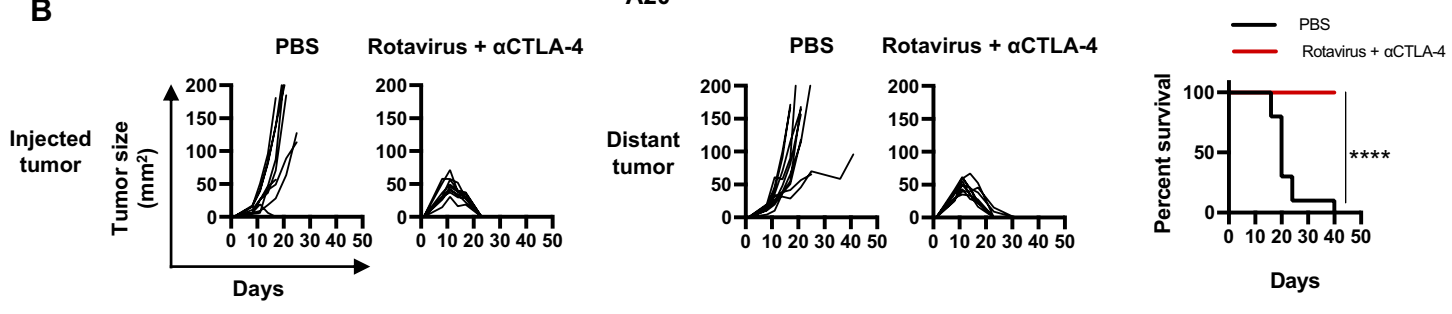

Neuro2a

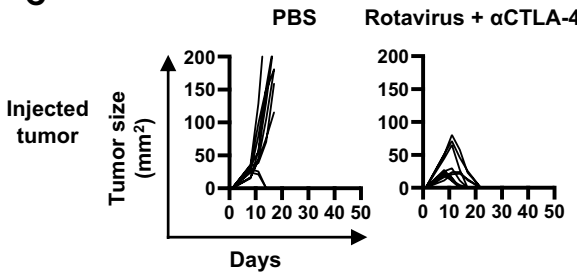

D

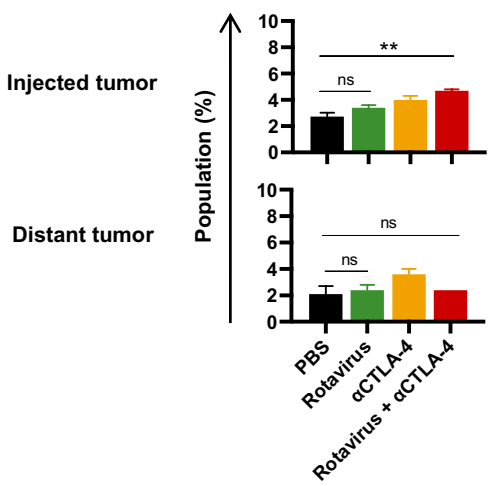

E

Distant tumor

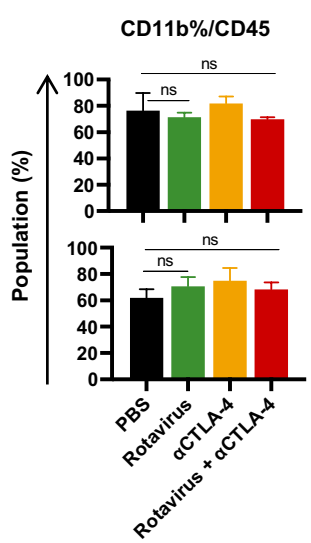

Injected tumo
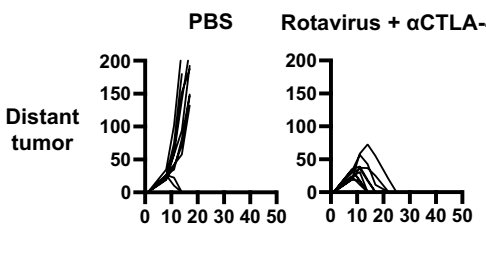

A20

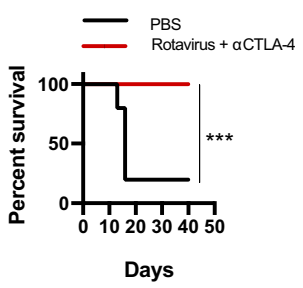

OX40\%/CD8
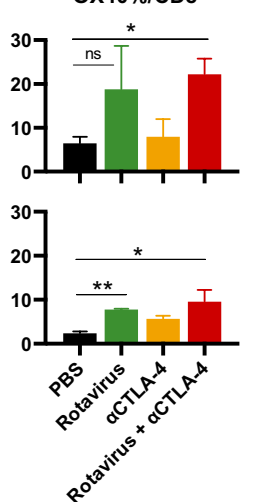

OX40\%/CD8

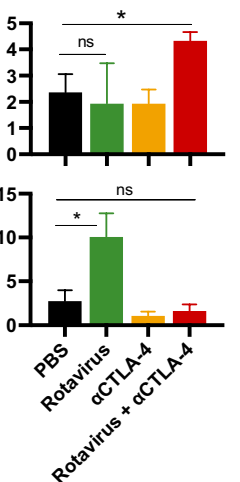

of pediatric cancers that are currently shown to be resistant to ICB mAbs $(29,30)$. While evaluating the TLR stimulating capacity of different viral- and bacterial-based vaccine, we identified that 
rotavirus vaccines have the capacity to stimulate NF- $\mathrm{KB}$ independently of TLRs and IRFs. The mechanism by which rotavirus can activate NF- $\kappa \mathrm{B}$ may be directed by one of the viral structural or nonstructural proteins. It has been shown that viral proteins interact with host proteins implicated in the type I IFN response (31). This activation could also be indirect via vaccine-induced cytotoxicity of cells, resulting in the release of damage-associated molecular patterns or the autocrine production of cytokines and the activation of different pathways leading to NF- $\kappa \mathrm{B}$ activation. Even if the cell death induced by rotavirus is not yet fully characterized, it harbors features of immunogenic cell death such as the release of ATP. We show here that IT rotavirus therapy has cancer cellselective cytotoxicity because it induces a cell lysis of all evaluated tumor lines at low dose $\left(\mathrm{IC}_{50}=1: 200,000\right.$ to $\left.1: 2000\right)$, whereas normal fibroblasts and primary HMEC viability are only affected at much higher dose $\left(\mathrm{IC}_{50}=1: 20\right.$ to $\left.1: 200\right)$. Recently, the team of Guerrero et al. (32) has reported similar results on the oncolytic properties of rotavirus against several cancer lines although with reduced potency compared to our results. We examined cells after 24 hours or more instead of 12 hours and also used strains selected for commercial vaccines, which were not the same as the Guerrero et al. (32) study.

As shown by the detection of $\mathrm{MxA}$ and the transcriptomic data, the in vivo injection of rotavirus leads to IT type I IFN induction, possibly in cancer cells or tumor-infiltrating immune cells. In this context, we also observed activation of tumor-infiltrating myeloid cells (up-regulation of CD80 and CD86) and CD8 T lymphocytes (up-regulation of CD137 and OX40; higher proportion of IFN $-\gamma^{+}$cells), which demonstrates the immunostimulating properties of the virus.

This activation of the immune response by the virus leads to a potent therapeutic activity when combined with IP anti-CTLA-4 and PD-(L)1 in ICB-resistant pediatric tumor models. As expected, the therapeutic activity of the combination of rotavirus and antiCTLA-4 was mainly CD8 T cell dependent. However, we did not study the potential role of $B$ cells and humoral response. We cannot exclude the possibility that IT rotavirus and/or ICB antibodies could trigger or stimulate an antitumor antibody systemic response contributing to the therapeutic effect against noninjected tumors. This hypothesis is supported by the fact that, in humans, IT oncolytic virus has been shown to increase the proportion of tumorinfiltrating $\mathrm{CD} 20^{+} \mathrm{B}$ cells in responding patients (33).

We observed the same synergistic effects with inactivated IT rotavirus than with active virus in the A20 lymphoma model. This effect is probably due to the fact that even heat- and UV-inactivated rotavirus has the ability to induce type I IFN signaling and acute inflammation. Physically inactivated rotavirus keeps a number of adjuvant properties due to PRR agonism. The use of mice-bearing tumors on two different sites allowed us to demonstrate a clear systemic antitumor effect of the combination of IT rotavirus with IP anti-CTLA-4 with complete regressions of both the injected and noninjected tumors in $100 \%$ of the mice treated. In addition, we observed immune cell activation in both tumor sites. Our work is in concordance with previous work, reporting that IT injections of the Newcastle disease murine oncolytic virus could overcome a systemic resistance to anti-CTLA-4 therapy in a mouse melanoma model (24) and that IT talimogene laherparepvec (T-VEC) virotherapy might improve anti-PD-1 immunotherapy in patients with metastatic melanoma (33). Through the induction of tumor immuno- genic cell death and the production of type I IFN, IT rotavirus injection is leading to an activation of the myeloid antigen-presenting cells likely resulting to a CD8 T cell priming. CTLA-4 and its ligands (CD80 and CD86) are up-regulated upon rotavirus injections on $\mathrm{T}$ cells and myeloid cells, respectively, supporting the potent synergy seen between rotavirus and anti-CTLA-4. In addition, CTLA- 4 was induced on CD4 ${ }^{+} \mathrm{T}$ cells and notably on $\mathrm{T}_{\text {regs }}$ upon IT rotavirus treatment. Because anti-CTLA-4 isotypes used in mice and humans have antibody-derived cell cytotoxicity properties, anti-CTLA-4 therapy might have depleted these immunosuppressive CTLA $-4^{+} \mathrm{CD} 4^{+} \mathrm{T}$ cells and prevent the negative feedback loop generated by IT type I IFN signaling.

In our preclinical testing, IT rotavirus was superior to systemic rotavirus when used in combination with anti-CTLA-4. However, the systemic delivery had some antitumor activity, and it is possible that the combination of IT rotavirus followed or combined with an intravenous delivery could be of interest, especially in the clinical settings where repeated intravenous infusions are easier than repeated IT injections. The advantage of IT injections of rotavirus is that it should prevent the side effects of systemic exposures and would allow the use of commercially available rotavirus vaccines. Furthermore, similar to T-VEC, IT injections of a high viral load could prevent virus neutralization in rotavirus-immunized patients because we obtained the same efficiency in immunized and nonimmunized mice in our preclinical experiment. A previous observation showed that preexisting immunity to a virus could potentiate its immunotherapeutic efficacy (34), which is not a phenomenon we observed with preexisiting immunity to rotavirus in our tumor models. In addition, the limited number of genes that are commonly up-regulated by EMT6 and A20 with either active or inactive rotavirus emphasizes that there might be common pathways that could be activated across cancer types with potential universal combinatorial benefits. It is likely that the RIG-I up-regulation follows the intracellular recognition of the rotavirus dsRNA and subsequently triggers a type I IFN pathway activation. The fact that RIG-I and IRF7 were among the top six common genes up-regulated upon rotavirus exposure suggests that this dsRNA sensor and its downstream type I IFN pathway might be critical to overcome antiCTLA-4 resistance. This result is of particular significance because the first IT synthetic RIG-I agonists have been recently launched in the clinic (NCT03739138 and NCT02828098). However, it is possible that such IT combination therapy is only required for patients bearing cancers with somatic inactivating mutations in specific genes involved in the type I IFN pathway. A comprehensive description of the tumor genome mutations would therefore be useful in clinical trials to better assess the role of type I IFN signaling in immunotherapy responses.

Together, our results provide the preclinical rationale in favor of IT rotavirus therapy to overcome anti-CTLA-4 cancer immunotherapy resistance, notably in pediatric cancers. Such clinical translation should be feasible with the use of rotavirus vaccines, which represent a clinical-grade, pediatric-approved, nongenetically modified source of oncolytic virus.

\section{MATERIALS AND METHODS Study design}

The study aimed at building a rationale for IT immunotherapy in cancer types such as pediatric cancers that are refractory to ICB 
therapies. First, we identified clinical sources of TLR agonists among the commercially available anti-infectious disease vaccines. We then tested the oncolytic properties of rotavirus vaccines and rotavirus strains with in vitro cytotoxic assays against both murine and human cancer lines and controlled their selectivity with nonmalignant cell lines. We also tested the in vivo antitumor activity of IT anti-infectious vaccines against a syngeneic immunocompetent neuroblastoma that is refractory to ICB therapies and confirmed activity in two additional models. Gene expression analysis was performed to identify pathways involved in rotavirus activity. We confirmed the synergy of IT rotavirus and systemic ICB therapy in two additional models, which are partially sensitive to ICB therapy. Further experiments were performed to determine abscopal effect and immune cell subset contributions to protection. All in vitro and in vivo experiments were unblinded but performed in replicates with appropriate controls. For in vivo therapy experiments, mice were treated only after tumors were established (i.e., diameter of $>0.5 \mathrm{~mm}$, which typically happens between days 5 and 7 after tumor challenge). To ensure statistical power, experimental groups were typically composed of more than five animals per group. For each experiment, group size, conditions, statistical tests, and numbers of experimental replicates are described in the figure legends. Data include all outliers. Primary data used to make figures are reported in data file S1. Gene expression data are provided in data file S2.

\section{Vaccines}

Commercially available vaccines were purchased via the Léon Bérard Cancer Center pharmacy: BCG (Medac), Tyavax (Sanofi Pasteur MSD), Imovaxpolio (Sanofi Pasteur MSD), Rouvax (Sanofi Pasteur MSD), Stamaril (Sanofi Pasteur MSD), Infanrix [GlaxoSmithKline (GSK)], Cervarix (GSK), Pneumo 23 (Sanofi Pasteur MSD), TicoVac (Baxter), Tetanic (Sanofi Pasteur MSD), Priorix (GSK), and Twinrix (GSK). Rotavirus vaccines Rotarix (GSK) and Rotateq (Sanofi Pasteur MSD) have been both tested in the experiments and will be referred as rotavirus vaccines throughout the manuscript. Because multiplicity of infections cannot be established for these commercial vaccines, dilutions in culture media of pure vaccines/virus have been used for in vitro experiments. To decipher the impact of the rotavirus versus the excipients in the rotavirus vaccines, a rotavirus vaccinal strain stock and pure excipient were provided by MSD through a material transfer agreement (MTA).

Mice were immunized two times by oral administration of $6 \mu \mathrm{l}$ of Rotateq vaccine (days -15 and -7 ) before tumor engraftment. Rotavirus strains were inactivated at $60^{\circ} \mathrm{C}$ for 4 hours, followed by 2 hours of UV irradiation.

\section{Cell cultures}

Cell lines SH-SY5Y [CRL-2266, American Type Culture Collection (ATCC)], SKBR3 (HTB-30, ATCC), SH-EP1 (CRL-2269, ATCC), CT26 (CRL-2638, ATCC), H1299 (CRL-5803, ATCC), RD-ES (HTB166, ATCC), POE [Ewing sarcoma cell line (35)], OE19 (96071721, European Collection of Authenticated Cell Cultures), Me Mon (CRL-1342, ATCC), and KD [Rhabdoïd tumor cell line (36)] were cultured in RPMI 1640 medium (Gibco, Life Technologies) supplemented with $10 \%$ of heat-inactivated fetal bovine serum (FBS), 1\% L-glutamine, and 1\% antibiotic (penicillin and streptomycin; Life Technologies). 4T1 (CRL-2539, ATCC) was cultured in RPMI 1640 supplemented as described above and completed with $\beta$-mercaptoethanol $(50 \mu \mathrm{M})$. The cell lines DU145 (HTB-81,
ATCC), LNCaP (CRL-1740, ATCC), U-87 (HTB-14, ATCC), U251 (HTB-17, ATCC), and A172 (CRL-1620, ATCC) were cultured in RPMI 1640 supplemented as described above and completed with nonessential amino acids $(1 \times)$. The cell lines Neuro2a (CCL-131, ATCC), NXS2 [previously described and provided by Sondel and colleagues (37)], MDA MB231 (HTB-26, ATCC), SKBR3 (HTB-30, ATCC), T47D (HTB-133, ATCC), CAMA-1 (HTB-21, ATCC), HepG2 (HB-8065, ATCC), Hep3B (HB-8064, ATCC), SK-HEP-1 (HTB-52, ATCC), ACHN (CRL-1611, ATCC), Caki-1 (HTB-46, ATCC), and Calu-1 (HTB-54, ATCC) were cultured in Dulbecco's modified Eagle's medium (DMEM) supplemented as mentioned above. BTB474 (HTB-20, ATCC) was cultured in DMEM supplemented as described above and completed with $7.5 \%$ bicarbonate sodium (S8761, Sigma-Aldrich). MCF7 (HTB-22, ATCC) was cultured in DMEM supplemented as described above and completed with insulin (2.5 U/ml; NovoRapid). Transgenic hTLR-LUC cell lines were provided by Transgene and were seeded in DMEM (Gibco, Life Technologies) supplemented as described before. Each cell line was selected by its respective antibiotic (TLR 2 and TLR 4 by Zeocin, Hygromycin, and Blasticidin, TLR3, TLR5 to TLR9 by Zeocin and Blasticidin, and LUC by Zeocin). All cell lines were incubated at $37^{\circ} \mathrm{C}$ at $5 \% \mathrm{CO}_{2}$. The A20 murine B cell lymphoma cell line syngeneic to Balb/c mice was a gift from Ronald Levy lab (Stanford University) and was cultured with RPMI 1640 supplemented as mentioned above. EMT6 (CRL-2755, ATCC) was cultured in Waymouth MB752/1 medium (W1625, Sigma-Aldrich) supplemented with 1\% L-glutamine, $15 \%$ FBS, and $1 \%$ antibiotic (penicillin and streptomycin). Skin fibroblast cell lines from Caucasian individuals were obtained from the cell culture collections of the Centre de Biotechnologie Cellulaire (CBC-Biotec, CRB-Hospices Civils de Lyon, France). HMEC (PCS-600-010, ATCC) cell lines were cultured in mammary epithelial cell basal medium (PCS-600-030, ATCC) enriched with mammary epithelial cell growth kit (PCS-600-040, ATCC).

\section{Bioluminescence assays}

Human embryonic kidney (HEK) 293 cells were stably transfected with plasmids, allowing the constitutive expression of TLRs of human origin (hTLRs) (InvivoGen). To generate a reporter model of TLR activation, HEK-293 cells stably expressing hTLRs or control HEK-293 cells were then stably transfected with the NF- $\kappa B-$ inducible reporter plasmid pNiFty-luc (InvivoGen) using the calcium phosphate method. Stable transfectants were selected in the presence of Zeocin ( $100 \mu \mathrm{g} / \mathrm{ml}$; InvivoGen). For stimulation assays, cells were seeded in DMEM supplemented on flat-bottom 96-well plates. The next day, medium was replaced by fresh medium and respective ligands. Cells were lysed (18 to 20 hours later) in $30 \mu \mathrm{l}$ of $5 \times$ lysis buffer (Promega). Firefly luciferase activity was quantified using $20 \mu \mathrm{l}$ of lysate by integrated measurement of flash luminescence over $1 \mathrm{~s}$ (Berthold TriStar LB 941, Grenier) in 96 wells after injection of $20 \mu \mathrm{l}$ of $1 \times$ "in-house" luciferase revelation buffer [ $20 \mathrm{mM}$ tris ( $\mathrm{pH} 7.8$ ), $1.07 \mathrm{mM} \mathrm{MgCl} 2,2.7 \mathrm{mM} \mathrm{MgSO}_{4}, 0.1 \mathrm{mM}$ EDTA, $33.3 \mathrm{mM}$ dithiothreitol, $470 \mu \mathrm{M}$ luciferine, $530 \mu \mathrm{M}$ ATP, and $270 \mu \mathrm{M}$ coenzyme A] by TECAN spectra plate reader machine.

\section{Cytotoxicity tests (SRB assay)}

SRB assay (TOX6-1KT, Sigma-Aldrich) was used to evaluate the cytotoxicity activity of different dilutions of rotavirus vaccine/strain on human tumoral cells. Triton X-100 (0.1\%) was used as the positive control. Briefly, cancer cells $(10,000)$ were plated in a 96 -well plate 
and then treated with serial dilutions of rotavirus vaccine/virus in medium for 3 to 5 days. The treated cells were fixed with $50 \mu \mathrm{l}$ of $10 \%$ cold trichloroacetic acid solution for 1 hour at $4^{\circ} \mathrm{C}$, washed five times with distilled water, and then dried at room temperature. The dried cells were stained with $100 \mu \mathrm{l}$ of $0.4 \%$ SRB for $30 \mathrm{~min}$ and rinsed five times with $1 \%$ acetic acid solution. Last, the dye was dissolved in $10 \mathrm{mM}$ tris buffer and measured at $565 \mathrm{~nm}$ on a TECAN spectra plate reader machine.

\section{Mice}

Six- to 8-week-old female $\mathrm{A} / \mathrm{J}$ and $\mathrm{Balb} / \mathrm{c}$ mice were purchased from Harlan, and the NSG mice were purchased from Charles River Laboratories. All the experiments were performed in the Leon Berard Center animal laboratory with the approval number: C69 388 0202. All the experiments were validated through ethics committee with the approval number: CECCAPP-CLB-2016-009 and CECCAPP-CLB-2018-017.

\section{Tumor transplantations}

A total of $5 \times 10^{6}$ cells of Neuro2a, Nxs2, A20, and CT26 or $1 \times 10^{5}$ cells of $4 \mathrm{~T} 1$ and $2 \times 10^{6}$ cells of EMT6 tumor cell lines in $100 \mu \mathrm{l}$ of $1 \times$ PBS were transplanted subcutaneously to the mice. Tumor sizes were monitored with a digital caliper (Mitutoyo) every 2 to 3 days and expressed as surface area (length $\times$ width). Mice were killed when subcutaneous tumor size reached $2 \mathrm{~cm}^{2}$.

\section{Tumor immunotherapy treatment}

Treatments started when tumors reached 0.7 to $1 \mathrm{~cm}$ in largest diameter, usually around day 7 after tumor inoculation. IT injections of rotavirus vaccine/strain $(100 \mu \mathrm{l}$ of the vaccine and $100 \mu \mathrm{l}$ of $1 / 100$ virus dilution) were performed three times, with 3-day intervals. The immune checkpoint-targeted antibodies anti-CTLA-4 (clone 9H10) or anti-PD-L1 (clone 10F.9G2) were purchased at Bio X Cell and were injected systemically via the IP route at the concentration of $200 \mu \mathrm{g}$ in $100 \mu \mathrm{l}$ of PBS, four times with 3 days intervals (10 mice per group in each experiment).

\section{CD4/CD8 $T$ and NK cell depletions}

Anti-CD4 (rat IgG2b; clone GK1.5), anti-CD8a (rat IgG2b; clone 2.43), and anti-asialo GM1 (polyclonal anti-mouse rabbit immunoglobulins) depleting mAbs were purchased from Bio X Cell and Wako Chemicals. Anti-CD4 or -CD8 antibodies $(200 \mu \mathrm{g})$ were injected intraperitoneally 2 and 1 days before starting the IT rotavirus therapy and 5 and 8 days after beginning of the therapy. To deplete NK cells, mice were injected intraperitoneally with $50 \mu \mathrm{l}$ of antiasialo GM1 antibody (Wako Chemicals) in $200 \mu$ of PBS 24 hours before starting the IT rotavirus therapy.

\section{Flow cytometry}

Tumors, lymph nodes, and spleens were turned into single-cell suspensions by processing them through a $70-\mu \mathrm{m}$ cell strainer. A total of $1 \times 10^{6}$ cells were surface-stained in $1 \times$ PBS using $1 \mu \mathrm{g}$ of antibodies. Mouse Fc receptors were blocked with $1 \mu \mathrm{g}$ of Fc $\gamma$ RIII/II-specific antibody (rat IgG2b $\kappa$; clone 2.4G2, BD Biosciences). Staining antibodies directed against CD45 (clone 30-F11), CD8 (clone 53-6.7), CD4 (clone GK1.5), Foxp3 (clone FJK-16S), CTLA-4 (clone UC10-4B9), Ox40 (clone ox-86), CD137 (clone 17B5), and IFN- $\gamma$ (clone XMG1.2) were purchased from eBioscience. Intracellular staining was performed using Foxp3 staining kit (00-5523-00), and intra- cellular fixation and permeabilization buffer (88-8824-00) and brefeldin A (00-4506-51) were also purchased from eBioscience. Staining antibodies directed against CD3 (clone 17A2), CD11b (clone M1/70), and PD-L1 (clone 29E2A3) were purchased from BioLegend. Staining antibodies directed against CD14 (clone M5E2), CD64 (clone 10.1), CD163 (clone GHI/61), CD80 (clone L307.4), CD86 [clone 2331 (FUN1)], and human leukocyte antigen DR (clone G48-6) were purchased from BD Biosciences. The stained cells were acquired by flow cytometry on a FACS (fluorescence-activated cell sorting) Canto II (BD Biosciences) and analyzed on the FACS Diva software.

\section{Immunofluorescence in situ}

Immunofluorescence stainings were performed on frozen tumor samples without blocking, using mouse anti-MxA (2G12; NPB1$47859)$ provided by Novus Biologicals and goat anti-mouse antibody conjugated to fluorescein isothiocyanate (00030748) provided by Dako. The incubation time for each staining step was maximum of 1 hour at room temperature. Secondary antibody alone was used as a control for the staining. The mean of immunofluorescence intensity was measured using the ImageJ software.

\section{Human peripheral blood mononuclear cell-derived macrophage preparation and M1/M2 macrophage polarization}

Human peripheral blood mononuclear cell (PBMC) from healthy donors was purchased from Etablissements Français du Sang, diluted $2 \times$ with PBS, and separated via Ficoll density gradients (CMSMSL01-01, Eurobio). Second density gradient separations were performed by Percoll PLUS (17-5445-01, GE Healthcare). Human monocytes were positively selected using monocyte isolation kit II human (130-091-153, Miltenyi Biotec), then planted into the dish, and cultured in RPMI 1640 supplemented with 10\% FBS. Macrophages were treated in vitro with recombinant human macrophage colony-stimulating factor $(25 \mathrm{ng} / \mathrm{ml}$; 300-25, PeproTech). M2 polarization was achieved by further treatment on day 5 with IL-4 (20 ng/ml; 200-04, PeproTech). M1 polarization was achieved with further treatment on day 5 by IFN- $\gamma(20 \mathrm{ng} / \mathrm{ml}$; 300-02, PeproTech), followed by lipopolysaccharide stimulation 24 hours later (day 6) (100 ng/ml; Sigma-Aldrich). Flow cytometry analyses were performed on day 7 to verify for the M1 and M2 phenotype. At day 7 , the macrophages were incubated with live or inactivated rotavirus for 48 and 96 hours.

\section{Splenocyte stimulation with cancer cells}

Splenocytes from cured and control mice were exposed to tumor cell line for 4 days in vitro. The ratio of splenocytes to tumor cell line was 1000:1 in RPMI 1640/DMEM. After 4 days, cells were treated with brefeldin A for 5 hours at $37^{\circ} \mathrm{C}$. Then, the surface markers and intracellular IFN- $\gamma$ were analyzed by flow cytometry using the above-mentioned antibodies and intracellular fixation and permeabilization buffer (88-8824-00, eBioscience).

\section{ATP release study}

ATP release was determined by CellTiter-Glo Luminescent Cell Viability Assay kit purchased from Promega.

\section{RNA isolation and Nanostring nCounter}

Transcriptomic analyses were performed in vitro on A20 and EMT6 cancer cell lines and in vivo on A20 tumors with or without 
IT rotavirus exposure (see details in figure legends). The samples were submitted for phenol extraction to isolate total RNA using TRI Reagent (T9424, Sigma-Aldrich). The analyses performed on samples were processed with the nCounter analysis system and ready-to-use LBL-C0268-02_nCounter_Mouse_Immunology_ Panel mouse immunology panel, which contains 770 unique mRNA barcodes. The data were processed using the NanoString Technology nSolver analysis software and with the support from the bioinformatic platform of the Leon Berard Cancer Research Center.

\section{Gene expression analysis}

Genes differentially expressed between in vitro by cancer cell lines or in vivo by tumors and control groups were determined with the DESeq2 R package (38). Only genes with a $\mid \log _{2}$ fold change $\mid$ of $>1$ and a $P \leq 0.005$ were retained for further analysis.

\section{Statistical analysis}

The Prism software version 6.0 (GraphPad) was used to display the tumor growth, to generate the bar charts, and to determine the statistical significance of differences between groups by applying one- or two-tailed Student's $t$ tests (depending on the predefined expectation of the direction of the result), and these tests were paired or unpaired depending on the settings of the experiment. Comparisons of means between more than two groups were performed by analysis of variance (ANOVA). Kaplan-Meier plots were used to analyze the survivals. Comparisons of survival curves were made using the log-rank test. $P$ values of less than 0.05 were considered significant.

\section{SUPPLEMENTARY MATERIALS}

Fig. S1. Proinflammatory features of anti-infectious disease vaccines.

Fig. S2. Immune gene expression of A20 tumor cells upon in vitro active and inactivated rotavirus exposure.

Fig. S3. Number of genes differentially expressed upon exposure of A20 cells with active or inactivated rotavirus in vitro.

Fig. S4. Immune gene expression of A20 tumors upon in vivo active and inactivated rotavirus exposure.

Fig. S5. Impact of in vitro rotavirus exposure on human myeloid cells.

Table S1. Contingency table of the number of genes differentially expressed (steady, up-regulated, or down-regulated) between EMT6 and A20 cancer cell lines upon rotavirus exposure.

Table S2. Number of genes commonly regulated between A20 and EMT6 cancer cell lines upon rotavirus exposure.

Table S3. Number of genes commonly regulated upon exposure of A20 cancer cells with active rotavirus or inactivated rotavirus in comparison with control media.

Table S4. Genes differentially expressed by A20 tumors in vivo upon active versus inactivated IT rotavirus therapy.

Data file S1. Primary data.

Data file S2. Gene expression data.

\section{REFERENCES AND NOTES}

1. L. Hirsch, L. Zitvogel, A. Eggermont, A. Marabelle, PD-Loma: A cancer entity with a shared sensitivity to the PD-1/PD-L1 pathway blockade. Br. J. Cancer 120, 3-5 (2019).

2. S. L. Topalian, J. M. Taube, R. A. Anders, D. M. Pardoll, Mechanism-driven biomarkers to guide immune checkpoint blockade in cancer therapy. Nat. Rev. Cancer 16, 275-287 (2016).

3. G. T. Gibney, L. M. Weiner, M. B. Atkins, Predictive biomarkers for checkpoint inhibitorbased immunotherapy. Lancet Oncol. 17, e542-e551 (2016).

4. P. C. Tumeh, C. L. Harview, J. H. Yearley, I. P. Shintaku, E. J. M. Taylor, L. Robert, B. Chmielowski, M. Spasic, G. Henry, V. Ciobanu, A. N. West, M. Carmona, C. Kivork, E. Seja, G. Cherry, A. J. Gutierrez, T. R. Grogan, C. Mateus, G. Tomasic, J. A. Glaspy, R. O. Emerson, H. Robins, R. H. Pierce, D. A. Elashoff, C. Robert, A. Ribas, PD-1 blockade induces responses by inhibiting adaptive immune resistance. Nature 515, 568-571 (2014).
5. A. Snyder, V. Makarov, T. Merghoub, J. Yuan, J. M. Zaretsky, A. Desrichard, L. A. Walsh, M. a. Postow, P. Wong, T. S. Ho, T. J. Hollmann, C. Bruggeman, K. Kannan, Y. Li, C. Elipenahli, C. Liu, C. T. Harbison, L. Wang, A. Ribas, J. D. Wolchok, T. a. Chan, Genetic basis for clinical response to CTLA-4 blockade in melanoma. N. Engl. J. Med. 371, 2189-2199 (2014).

6. N. A. Rizvi, M. D. Hellmann, A. Snyder, P. Kvistborg, V. Makarov, J. J. Havel, W. Lee, J. Yuan, P. Wong, T. S. Ho, M. L. Miller, N. Rekhtman, A. L. Moreira, F. Ibrahim, C. Bruggeman, B. Gasmi, R. Zappasodi, Y. Maeda, C. Sander, E. B. Garon, T. Merghoub, J. D. Wolchok, T. N. Schumacher, T. A. Chan, Mutational landscape determines sensitivity to PD-1 blockade in non-small cell lung cancer. Science 348, 124-128 (2015).

7. E. Romano, M. Kusio-Kobialka, P. G. Foukas, P. Baumgaertner, C. Meyer, P. Ballabeni, O. Michielin, B. Weide, P. Romero, D. E. Speiser, Ipilimumab-dependent cell-mediated cytotoxicity of regulatory $T$ cells ex vivo by nonclassical monocytes in melanoma patients. Proc. Natl. Acad. Sci. U.S.A. 112, 6140-6145 (2015).

8. C. Gebhardt, A. Sevko, H. Jiang, R. Lichtenberger, M. Reith, K. Tarnanidis, T. Holland-Letz, L. Umansky, P. Beckhove, A. Sucker, D. Schadendorf, J. Utikal, V. Umansky, Myeloid cells and related chronic inflammatory factors as novel predictive markers in melanoma treatment with ipilimumab. Clin. Cancer Res. 21, 5453-5359 (2015).

9. D. S. Shin, J. M. Zaretsky, H. Escuin-Ordinas, A. Garcia-Diaz, S. Hu-Lieskovan, A. Kalbasi, C. S. Grasso, W. Hugo, S. Sandoval, D. Y. Torrejon, N. Palaskas, G. A. Rodriguez, G. Parisi, A. Azhdam, B. Chmielowski, G. Cherry, E. Seja, B. Berent-Maoz, I. P. Shintaku, D. T. Le, D. M. Pardoll, L. A. Diaz, P. C. Tumeh, T. G. Graeber, R. S. Lo, B. Comin-Anduix, A. Ribas, Primary resistance to PD-1 blockade mediated by JAK1/2 mutations. Cancer Discov. 7 , 188-201 (2017).

10. J. M. Zaretsky, A. Garcia-Diaz, D. S. Shin, H. Escuin-Ordinas, W. Hugo, S. Hu-Lieskovan, D. Y. Torrejon, G. Abril-Rodriguez, S. Sandoval, L. Barthly, J. Saco, B. Homet Moreno, R. Mezzadra, B. Chmielowski, K. Ruchalski, I. P. Shintaku, P. J. Sanchez, C. Puig-Saus, G. Cherry, E. Seja, X. Kong, J. Pang, B. Berent-Maoz, B. Comin-Anduix, T. G. Graeber, P. C. Tumeh, T. N. M. Schumacher, R. S. Lo, A. Ribas, Mutations associated with acquired resistance to PD-1 blockade in melanoma. N. Engl. J. Med. 375, 819-829 (2016).

11. J. Vakkila, R. Jaffe, M. Michelow, M. T. Lotze, Pediatric cancers are infiltrated predominantly by macrophages and contain a paucity of dendritic cells: A major nosologic difference with adult tumors. Clin. Cancer Res. 12, 2049-2054 (2006).

12. S. Asgharzadeh, J. A. Salo, L. Ji, A. Oberthuer, M. Fischer, F. Berthold, M. Hadjidaniel, C. W.-Y. Liu, L. S. Metelitsa, R. Pique-Regi, P. Wakamatsu, J. G. Villablanca, S. G. Kreissman, K. K. Matthay, H. Shimada, W. B. London, R. Sposto, R. C. Seeger, Clinical significance of tumor-associated inflammatory cells in metastatic neuroblastoma. J. Clin. Oncol. 30, 3525-3532 (2012).

13. J. J. Molenaar, J. Koster, D. A. Zwijnenburg, P. van Sluis, L. J. Valentijn, I. van der Ploeg, M. Hamdi, J. van Nes, B. A. Westerman, J. van Arkel, M. E. Ebus, F. Haneveld, A. Lakeman, L. Schild, P. Molenaar, P. Stroeken, M. M. van Noesel, I. Ora, E. E. Santo, H. N. Caron, E. M. Westerhout, R. Versteeg, Sequencing of neuroblastoma identifies chromothripsis and defects in neuritogenesis genes. Nature 483, 589-593 (2012).

14. T. J. Pugh, O. Morozova, E. F. Attiyeh, S. Asgharzadeh, J. S. Wei, D. Auclair, S. L. Carter, K. Cibulskis, M. Hanna, A. Kiezun, J. Kim, M. S. Lawrence, L. Lichenstein, A. McKenna, C. S. Pedamallu, A. H. Ramos, E. Shefler, A. Sivachenko, C. Sougnez, C. Stewart, A. Ally, I. Birol, R. Chiu, R. D. Corbett, M. Hirst, S. D. Jackman, B. Kamoh, A. H. Khodabakshi, M. Krzywinski, A. Lo, R. A. Moore, K. L. Mungall, J. Qian, A. Tam, N. Thiessen, Y. Zhao, K. A. Cole, M. Diamond, S. J. Diskin, Y. P. Mosse, A. C. Wood, L. Ji, R. Sposto, T. Badgett, W. B. London, Y. Moyer, J. M. Gastier-Foster, M. A. Smith, J. M. G. Auvil, D. S. Gerhard, M. D. Hogarty, S. J. M. Jones, E. S. Lander, S. B. Gabriel, G. Getz, R. C. Seeger, J. Khan, M. A. Marra, M. Meyerson, J. M. Maris, The genetic landscape of high-risk neuroblastoma. Nat. Genet. 45, 279-284 (2013).

15. R. Lee, C. Stewart, S. Carter, L. Ambrogio, K. Cibulskis, C. Sougnez, M. S. Lawrence, D. Auclair, J. Mora, T. R. Golub, J. A. Biegel, G. Getz, C. W. Roberts, A remarkably simple genome underlies highly malignant pediatric rhabdoid cancers. J. Clin. Invest. 122, 2983-2988 (2012)

16. T. Fujiwara, J. Fukushi, S. Yamamoto, Y. Matsumoto, N. Setsu, Y. Oda, H. Yamada, S. Okada, K. Watari, M. Ono, M. Kuwano, S. Kamura, K. lida, Y. Okada, M. Koga, Y. Iwamoto, Macrophage infiltration predicts a poor prognosis for human ewing sarcoma. Am. J. Pathol. 179, 1157-1170 (2011).

17. A. Marabelle, L. Tselikas, T. de Baere, R. Houot, Intratumoral immunotherapy: Using the tumor as the remedy. Ann. Oncol. 28, xii33-xii43 (2017).

18. M. A. Aznar, N. Tinari, A. J. Rullán, A. R. Sánchez-Paulete, M. E. Rodriguez-Ruiz, I. Melero, Intratumoral delivery of immunotherapy-act locally, think globally. J. Immunol. 198, 31-39 (2017).

19. T. Shekarian, S. Valsesia-Wittmann, J. Brody, M. C. C. Michallet, S. Depil, C. Caux, A. Marabelle, Pattern recognition receptors: Immune targets to enhance cancer immunotherapy. Ann. Oncol. 28, 1756-1766 (2017).

20. J. D. Brody, W. Z. Ai, D. K. Czerwinski, J. A. Torchia, M. Levy, R. H. Advani, Y. H. Kim, R. T. Hoppe, S. J. Knox, L. K. Shin, I. Wapnir, R. J. Tibshirani, R. Levy, In situ vaccination 
with a TLR9 agonist induces systemic lymphoma regression: A phase I/II study. J. Clin. Oncol. 28, 4324-4332 (2010).

21. Y. H. Kim, D. Gratzinger, C. Harrison, J. D. Brody, D. K. Czerwinski, W. Z. Ai, A. Morales, F. Abdulla, L. Xing, D. Navi, R. J. Tibshirani, R. H. Advani, B. Lingala, S. Shah, R. T. Hoppe, R. Levy, In situ vaccination against mycosis fungoides by intratumoral injection of a TLR9 agonist combined with radiation: A phase 1/2 study. Blood 119, 355-363 (2012).

22. R. H. I. Andtbacka, H. L. Kaufman, F. Collichio, T. Amatruda, N. Senzer, J. Chesney, K. A. Delman, L. E. Spitler, I. Puzanov, S. S. Agarwala, M. Milhem, L. Cranmer, B. Curti, K. Lewis, M. Ross, T. Guthrie, G. P. Linette, G. A. Daniels, K. Harrington, M. R. Middleton, W. H. Miller, J. S. Zager, Y. Ye, B. Yao, A. Li, S. Doleman, A. VanderWalde, J. Gansert, R. S. Coffin, Talimogene laherparepvec improves durable response rate in patient with advanced melanoma. J. Clin. Oncol. 33, 2780-2788 (2015).

23. J. Fu, D. B. Kanne, M. Leong, L. H. Glickman, S. M. McWhirter, E. Lemmens, K. Mechette, J. J. Leong, P. Lauer, W. Liu, K. E. Sivick, Q. Zeng, K. C. Soares, L. Zheng, D. A. Portnoy, J. J. Woodward, D. M. Pardoll, T. W. Dubensky, Y. Kim, STING agonist formulated cancer vaccines can cure established tumors resistant to PD-1 blockade. Sci. Transl. Med. 7, 283ra52 (2015).

24. D. Zamarin, R. B. Holmgaard, S. K. Subudhi, J. S. Park, M. Mansour, P. Palese, T. Merghoub, J. D. Wolchok, J. P. Allison, Localized oncolytic virotherapy overcomes systemic tumor resistance to immune checkpoint blockade immunotherapy. Sci. Transl. Med. 6, $226 \mathrm{ra} 32$ (2014).

25. R. Houot, R. Levy, T-cell modulation combined with intratumoral CpG cures lymphoma in a mouse model without the need for chemotherapy. Blood 113, 3546-3552 (2009).

26. A. Marabelle, H. Kohrt, I. Sagiv-Barfi, B. Ajami, R. C. Axtell, G. Zhou, R. Rajapaksa, M. R. Green, J. Torchia, J. Brody, R. Luong, M. D. Rosenblum, L. Steinman, H. I. Levitsky, V. Tse, R. Levy, Depleting tumor-specific Tregs at a single site eradicates disseminated tumors. J. Clin. Invest. 123, 2447-2463 (2013).

27. I. Puzanov, M. M. Milhem, D. Minor, O. Hamid, A. Li, L. Chen, M. Chastain, K. S. Gorski, A. Anderson, J. Chou, H. L. Kaufman, R. H. I. Andtbacka, Talimogene laherparepvec in combination with ipilimumab in previously untreated, unresectable stage iiib-iv melanoma. J. Clin. Oncol. , 2447-2463 (2016).

28. G. V. Long, R. Dummer, A. Ribas, I. Puzanov, A. VanderWalde, R. H. I. Andtbacka, O. Michielin, A. J. Olszanski, J. Malvehy, J. S. Cebon, E. Fernandez, J. M. Kirkwood, T. Gajewski, C. K. Gause, L. Chen, K. Gorski, A. Anderson, D. R. Kaufman, J. Chou, F. S. Hodi, Efficacy analysis of MASTERKEY-265 phase $1 \mathrm{~b}$ study of talimogene laherparepvec (T-VEC) and pembrolizumab (pembro) for unresectable stage IIIB-IV melanoma. J. Clin. Oncol. 34, 9568-9568 (2016).

29. M. S. Merchant, M. Wright, K. Baird, L. H. Wexler, C. Rodriguez-Galindo, D. Bernstein, C. Delbrook, M. Lodish, R. Bishop, J. D. Wolchok, H. Streicher, C. L. Mackall, Phase I clinical trial of ipilimumab in pediatric patients with advanced solid tumors. Clin. Cancer Res. 22 1364-1370 (2015)

30. B. Geoerger, C. Bergeron, L. Gore, L. Sender, I. J. Dunkel, C. Herzog, L. Brochez, O. Cruz, K. Nysom, E. Berghorn, B. Simsek, J. Shen, A. Pappo, Phase II study of ipilimumab in adolescents with unresectable stage III or IV malignant melanoma. Eur. J. Cancer 86, 358-363 (2017).

31. M. Barro, J. T. Patton, Rotavirus NSP1 inhibits expression of type i interferon by antagonizing the function of interferon regulatory factors IRF3, IRF5, and IRF7. J. Virol. 81 4473-4481 (2007).

32. C. A. Guerrero, R. A. Guerrero, E. Silva, O. Acosta, E. Barreto, K. Roemer, Ed. Experimental adaptation of rotaviruses to tumor cell lines. PLOS ONE 11, e0147666 (2016).

33. A. Ribas, R. Dummer, I. Puzanov, A. VanderWalde, R. H. I. Andtbacka, O. Michielin, A. J. Olszanski, J. Malvehy, J. Cebon, E. Fernandez, J. M. Kirkwood, T. F. Gajewski, L. Chen, K. S. Gorski, A. A. Anderson, S. J. Diede, M. E. Lassman, J. Gansert, F. S. Hodi, G. V. Long,
Oncolytic virotherapy promotes intratumoral T cell infiltration and improves anti-PD-1 immunotherapy. Cell 170, 1109-1119.e10 (2017).

34. J. M. Ricca, A. Oseledchyk, T. Walther, C. Liu, L. Mangarin, T. Merghoub, J. D. Wolchok, D. Zamarin, Pre-existing immunity to oncolytic virus potentiates its immunotherapeutic efficacy. Mol. Ther. 26, 1008-1019 (2018).

35. F. Tirode, D. Surdez, X. Ma, M. Parker, M. C. Le Deley, A. Bahrami, Z. Zhang, E. Lapouble, S. Grossetete-Lalami, M. Rusch, S. Reynaud, T. Rio-Frio, E. Hedlund, G. Wu, X. Chen, G. Pierron, O. Oberlin, S. Zaidi, G. Lemmon, P. Gupta, B. Vadodaria, J. Easton, M. Gut, L. Ding, E. R. Mardis, R. K. Wilson, S. Shurtleff, V. Laurence, J. Michon, P. Marec-Berard, I. Gut, J. Downing, M. Dyer, J. Zhang, O. Delattre, Genomic landscape of ewing sarcoma defines an aggressive subtype with co-association of STAG2 and TP53 mutations. Cancer Discov. 4, 1342-1353 (2014).

36. M. F. Rousseau-Merck, I. Versteege, I. Legrand, J. Couturier, A. Mairal, O. Delattre, A. Aurias, $h$ SNF5/INI 1 inactivation is mainly associated with homozygous deletions and mitotic recombinations in rhabdoid tumors. Cancer Res. 59, 3152-3156 (1999).

37. R. K. Yang, N. A. Kalogriopoulos, A. L. Rakhmilevich, E. A. Ranheim, S. Seo, K. Kim, K. L. Alderson, J. Gan, R. A. Reisfeld, S. D. Gillies, J. A. Hank, P. M. Sondel, Intratumoral hu14.18-IL-2 (IC) induces local and systemic antitumor effects that involve both activated T and NK cells as well as enhanced IC retention. J. Immunol. 189, 2656-2664 (2012).

38. M. I. Love, W. Huber, S. Anders, Moderated estimation of fold change and dispersion for RNA-seq data with DESeq2. Genome Biol. 15, 550 (2014).

Acknowledgements: We would like to thank P. Berchard, M. Husson, D. Cogne, V. Dettling, and technical students for help in some of the experiments. We thank P. Sondel (University of Wisconsin) for providing the NXS2 murine neuroblastoma cell line. Funding: We thank the following structures for their help in funding this research project: Institut d'Hématologie et d'Oncologie Pédiatrique (IHOPe) (A.M.), La Ligue Contre le Cancer (S.V.-W.), the Institut National du Cancer (INCa) for support through the funding of the SIRIC of Lyon (LYRICAN, INCa-DGOS-Inserm_12563) (C.C.) and the PRTK14_061, LABEX DEVweCAN (ANR-10LABX-0061) of the University of Lyon, within the program "Investissements d'Avenir" organized by the French National Research Agency (ANR) (C.C.), and most of all the patients' organization charities Les Torocinelles, ALBEC, and 111 des Arts (A.M.). We would like to thank MSD for providing the rotavirus strains of Rotateq. Author contributions: Data acquisition and primary analysis: T.S., A.-C.J., S.V.-W., J.K., N.G., C.C., and A.M. Study conception and design, data synthesis, statistical analysis, and manuscript preparation: T.S., E.S., S.D., J.K., I.-J.L., G.H., C.B., A.V., S.V.-W., C.C., and A.M. All the authors have seen and approved the final manuscript. Competing interests: The authors declare that they have no competing interests. Data and materials availability: The rotavirus vaccinal strain stock and pure excipient were provided by MSD through an MTA. All data associated with this study are present in the paper or the Supplementary Materials.

Citation: T. Shekarian, E. Sivado, A.-C. Jallas, S. Depil, J. Kielbassa, I. Janoueix-Lerosey, G. Hutter N. Goutagny, C. Bergeron, A. Viari, S. Valsesia-Wittmann, C. Caux, A. Marabelle, Repurposing rotavirus vaccines for intratumoral immunotherapy can overcome resistance to immune checkpoint blockade. Sci. Transl. Med. 11, eaat5025 (2019). 
